\title{
Twinning behaviour of AZ31 Mg alloy alternately compressed in two orthogonal directions
}

$\operatorname{AUTHOR}(\mathrm{S})$ :

Kwon, Hyukjoon; Nakano, Hiromi; Mabuchi, Mamoru; Chino, Yasumasa

\section{CITATION:}

Kwon, Hyukjoon ... [et al]. Twinning behaviour of AZ31 Mg alloy alternately compressed in two orthogonal directions. Philosophical Magazine 2014, 94(34): 3960-3977

ISSUE DATE:

2014-10-31

URL:

http://hdl.handle.net/2433/200204

\section{RIGHT:}

This is an Accepted Manuscript of an article published by Taylor \& Francis in 'Philosophical Magazine' on 31 Oct 2014 available online: http://www.tandfonline.com/10.1080/14786435.2014.973920.; The full-text file will be made open to the public on 31 Oct 2015 in accordance with publisher's 'Terms and Conditions for Self-Archiving'; This is not the published version. Please cite only the published version.; この論文は出版社版でありません。引用の際には出版社版 をご確認ご利用ください。 
Twinning behavior of AZ31 Mg alloy alternately-compressed in two orthogonal directions

Hyukjoon Kwon ${ }^{1}$, Hiromi Nakano ${ }^{2}$, Mamoru Mabuchi ${ }^{*}$ and Yasumasa Chino ${ }^{3}$

${ }^{1}$ Graduate School of Energy Science, Kyoto University,

Yoshida Honmachi, Sakyo-ku, Kyoto 606-8501, Japan

${ }^{2}$ Cooperative Research Facility Center, Toyohashi University of Technology,

Hibarigaoka, Tempaku-cho, Toyohashi 441-8580, Japan

${ }^{3}$ National Institute of Advanced Industrial Science and Technology, 2266-98 Anagahora, Shimo-shidami, Moriyama, Nagoya 463-8560, Japan

Hyukjoon Kwon

Department of Energy Science and Technology, Graduate School of Energy Science, Kyoto University,

Yoshidahonmachi, Sakyo-ku, Kyoto 606-8501, Japan

E-mail address: rrnjshj85@hotmail.com

Hiromi Nakano

Cooperative Research Facility Center, Toyohashi University of Technology,

Hibariga-oka, Tempaku, Toyohashi, 441-8580, Japan

E-mail: hiromi@crfc.tut.ac.jp 
Mamoru Mabuchi (corresponding author)

Department of Energy Science and Technology, Graduate School of Energy Science, Kyoto University,

Yoshidahonmachi, Sakyo-ku, Kyoto 606-8501, Japan

Tel: $+81-75-753-5404$

Fax: +81-75-753-5428

E-mail address: mabuchi@energy.kyoto-u.ac.jp

Yasumasa Chino

Materials Research Institute for Sustainable Development, National Institute of Advanced Industrial Science and Technology,

2266-98 Anagahora, Shimo-shidami, Moriyama, Nagoya 463-8560, Japan

E-mail address: y-chino@aist.go.jp 


\title{
Twinning behavior of AZ31 Mg alloy alternately-compressed in two orthogonal directions
}

\begin{abstract}
Extruded AZ31 Mg alloy was repeatedly alternately compressed in the extrusion direction (ED) and transverse direction (TD) at room temperature. The microstructures of compressed specimens were investigated by various analytical methods, e.g. electron backscattered diffraction, scanning electron microscopy and transmission electron microscopy. The specimen was not fractured even after 10-times alternate compressions, where the strain by each compression was about $12 \%$, although twinning increased with increasing compression number. $\{10 \overline{1} 1\}-\{10 \overline{1} 2\}$ double twins were generated during ED compression, but barely during TD compression. The double twins differed to those generated during deformation in one direction. $\{10 \overline{1} 2\}$ twinning outside the $\{10 \overline{1} 1\}$ twin induced $\{10 \overline{1} 2\}$ twinning inside the $\{10 \overline{1} 1\}$ twin, and consequently, $\{10 \overline{1} 1\}-\{10 \overline{1} 2\}$ double twins were formed during alternate compression. Hence, the geometric compatibility between $\{10 \overline{1} 2\}$ twins inside and outside the $\{10 \overline{1} 1\}$ twin was the determinant for the variant selection. Besides, dynamic recrystallization occurred at room temperature in the $\{10 \overline{1} 1\}$ twin, which resulted in a high ductility of the alternately-compressed specimens.
\end{abstract}

Keywords: magnesium alloy; compression test; deformation twinning; electron backscattered diffraction; recrystallization 


\section{Introduction}

Weight reduction of transported materials (e.g. aircraft, vessels, vehicles and contains) is important for minimizing $\mathrm{CO}_{2}$ emissions. Using $\mathrm{Mg}$ as a construction material is one of potential solutions because of its low weight and high specific strength and stiffness. $\mathrm{Mg}$ has sufficient number of potential slip systems, but only few of them are active or easily activated at room temperature. Hence, deformation twinning plays an important role in its plastic deformation at room temperature. Two main deformation twins in $\mathrm{Mg}$ are the $\{10 \overline{1} 2\}<10 \overline{1} 1>$ extension twin and the $\{10 \overline{1} 1\}<$ $10 \overline{1} 2>$ contraction twin [1-5]. $\{10 \overline{1} 2\}$ twinning occurs during the initial stage of deformation, or at a small strain. This is because its critical resolved shear stress (CRSS) is about 2-3 $\mathrm{MPa}[2]$, which is relatively low, and $\{10 \overline{1} 2\}$ twins grow readily. Also, $\{10 \overline{1} 2\}$ twinning causes large strain-hardening [3]. In particular, the interaction of $\{10 \overline{1} 2\}$ twins with different variants enhances the nucleation and propagation of $\{10 \overline{1} 2\}$ twinning, resulting in higher strain-hardening [6]. $\{10 \overline{1} 1\}$ twinning occurs at a large strain because of its high CRSS [7,8]. $\{10 \overline{1} 1\}$ twinning often results in premature fracture because $\{10 \overline{1} 1\}-\{10 \overline{1} 2\}$ double twins provide sites for crack nucleation $[9,10]$. A $\{10 \overline{1} 1\}-\{10 \overline{1} 2\}$ double twin is usually generated by the formation of a secondary $\{10 \overline{1} 2\}$ twin inside a primary $\{10 \overline{1} 1\}$ twin. There are four types of $\{10 \overline{1} 1\}-\{10 \overline{1} 2\}$ double twinning [11-15], type 1 being most commonly generated [11-16]. Atomic simulations have revealed the origin of nucleation for type 1 double twinning [17]. Single twinning of $\{10 \overline{1} 1\}$ or $\{10 \overline{1} 2\}$ often obeys the Schmid factor (SF) [18] although it does not always obeys it $[19,20]$, but secondary $\{10 \overline{1} 2\}$ twinning in the double twin does not in most cases [11-17]. Thus, the formation of double twinning is very complicated, even during deformation in one direction. 
$\{10 \overline{1} 2\}$ twinning-detwinning readily occurs during deformation in various directions, such as compressive pre-deformation and subsequent tensile deformation [21-26]. Wang et al. showed the glide and climb in twinning dislocations during $\{10 \overline{1} 2\}$ twinning and detwinning [27]. Yu et al. performed in-situ observations of $\{10 \overline{1} 2\}$ twinning-detwinning-retwinning [28], and showed that residual twins accumulated and resulted in microcracking. Thus, there is a reasonable understanding of $\{10 \overline{1} 2\}$ twinning during multiple deformation in various directions. Recently, $\{10 \overline{1} 1\}-\{10 \overline{1} 2\}$ interconnected twins were found to form during alternate compression in two orthogonal directions in AZ31 Mg alloy [29]. In this case, $\begin{cases}10 \overline{1} & 1\}\end{cases}$ twins were formed during compression, and $\{10 \overline{1} 2\}$ twins then interconnected with the $\{10 \overline{1} 1\}$ twins during subsequent compression in the orthogonal direction. Thus, alternate compression in two orthogonal directions were specifically needed for the generation of $\{10 \overline{1} 1\}-\{10 \overline{1} 2\}$ interconnected twins.

The present paper describes (1) effects of number of compressions on the flow stress, twin area fraction and texture, (2) $\{10 \overline{1} 1\}-\{10 \overline{1} 2\}$ double twinning, and (3) room temperature recrystallization during alternate compression in two orthogonal directions. In particular, the present paper highlights the origin of $\{10 \overline{1} 1\}-\{10 \overline{1} 2\}$ double twinning during alternate compression, which is different from that during simple compressive deformation. In addition, it is suggested in the present paper that room temperature recrystallization is caused by the formation of double twins and fine-grained microstructure is generated, resulting in enhanced ductility. These findings are of scientific interest because these are inherent in alternate compression in two orthogonal directions, and also they are important from technological view because products often fracture under external strain in various directions. A large strain for 
each deformation is needed for generation of $\{10 \overline{1} 1\}$ twins. Because it was difficult to investigate the twins by compressive pre-deformation and subsequent tensile deformation, alternate compression in two orthogonal directions was performed in the present work. It is impossible to regenerate $\{10 \overline{1} 2\}$ twins outside the $\{10 \overline{1} 1\}$ twins during simple compressive deformation since the loading directions are opposite for generation of the $\{10 \overline{1} 2\}$ twin and the $\{10 \overline{1} 1\}$ twin. However, in the case of alternate compression in two orthogonal directions, $\{10 \overline{1} 2\}$ twinning occurs outside the $\{10 \overline{1} 1\}$ twins. Thus, unique twinning behavior occurs during alternate compression in two orthogonal directions. In the present work, the selected variant of tertiary $\{10 \overline{1} 2\}$ twinning was investigated using the SF and geometric compatibility factor (GCF) [30].

\section{Experimental}

AZ31 Mg alloy (nominal chemical composition: Mg-2.8mass.\%Al-0.88mass.\%Zn-0.003mass.\%Mn) with coarse grained structure was used in this work. A Mg alloy ingot was extruded at $773 \mathrm{~K}$, at an extrusion ratio of 16:1, extrusion rate of $1 \mathrm{~mm} / \mathrm{min}$ and extrusion diameter of $10 \mathrm{~mm}$. A light microscopy (LM) image of the extrusion is shown in Fig. 1(a). The average grain size of the extrusion was $350 \mu \mathrm{m}$, as measured by the linear interception method. The (0002) pole figure of the extrusion is shown in Fig. 1(b). The (0002) basal planes were aligned intensely parallel to the extrusion direction (ED).

Specimens for alternate compression in two orthogonal directions were machined from the extruded $\mathrm{Mg}$ alloy. Specimens were cubic shaped with dimensions of $6.5 \times 6.5 \times 6.5 \mathrm{~mm}$. Alternate compression was performed at room temperature by 
compressing the specimens in the ED, and subsequently in the transverse direction (TD). The strain caused by each compression was about $12 \%$, and the initial compression strain rate was $1 \times 10^{-2} \mathrm{~s}^{-1}$. Alternate compression was repeated 10 times, namely, the first compression was carried out in the ED, the second compression in the TD, the third compression in the ED, and finally, the twentieth compression in the TD. In this paper, the compressions in the ED and the TD are called 1ED, 2TD, 3ED, $\cdots$, and 20TD. The microstructure of the specimens was investigated by LM, scanning electron microscopy (SEM, JSM-5910, JEOL, Japan) and transmission electron microscopy (TEM, JEM-2100F, JEOL, Japan). Specimens for LM and SEM observations were first etched for $3 \mathrm{~s}$ in a solution containing $20 \mathrm{ml}$ of acetic acid, $100 \mathrm{ml}$ of ethanol, $9 \mathrm{~g}$ of picric acid and $10 \mathrm{ml}$ of $\mathrm{H}_{2} \mathrm{O}$. Twin area fractions were measured in the specimens after the 3ED, the $4 \mathrm{TD}$, the $7 \mathrm{ED}$, the $8 \mathrm{TD}$, the $13 \mathrm{ED}$, the $14 \mathrm{TD}$, the $19 \mathrm{ED}$ and the $20 \mathrm{TD}$ compression using image analysis software (Image J $1.43 \mathrm{n}$, Japan). TEM observations were performed at an operating voltage of $200 \mathrm{kV}$. A TEM foil sample was taken from the site around the $\{10 \overline{1} 1\}$ twin and was produced by focused ion-beam (FIB) milling (JEM-9310FIB, JEOL, Japan). FIB milling was carried out at low energy to avoid heating the foil and introducing artifacts.

(0002) basal pole figures of the plane parallel to the ED were investigated by the Schulz reflection method. Standard $\theta-2 \theta$ scans were measured to determine the exact positions of peaks in texture measurements. The crystallographic reorientation caused by twinning was investigated by electron backscattered diffraction (EBSD) system (TexSEM Lab. Inc. USA), and the results were analyzed by $\mathrm{OIM}^{\mathrm{TM}} 7.0$ software. (TexSEM Lab. Inc. USA). Automated EBSD measurements were recorded with a scanning electron microscope. An accelerating voltage of $20 \mathrm{kV}$, working distance of 20 
$\mathrm{mm}$, sample tilt angle of $60^{\circ}$ and step size of $0.2 \mu \mathrm{m}$ were used for EBSD measurements. Samples for EBSD measurements were first ground with 2000 grit SiC paper, polished with 3 and then $1 \mu \mathrm{m}$ diamond suspension, polished with alumina suspension, and finally etched with ECR plasma ion shower equipment (Elionix Inc., EIS-200ER, Japan).

SF and GCF values for $\{10 \overline{1} 2\}$ twin systems with six variants in a $\{10 \overline{1} 1\}$ twin were calculated from Euler angles obtained from EBSD measurements to understand the origin of variant selection. The SF for twinning is given by:

$$
S F=\cos \theta \cos \lambda
$$

where $\theta$ is the angle between the loading direction and the normal to the twin plane, and $\lambda$ is the angle between the loading and shear directions. The GCF indicates the alignment of slip systems across a boundary. The transfer of slip between adjacent grains through a boundary has been estimated from the GCF [30-33]. The GCF for twinning is given by:

$$
G C F=\cos \Psi \cos K
$$

where $\Psi$ is the angle between the slip plane normals in two twins and $K$ is the angle between the twinning directions in two twins.

\section{Results and discussion}

\subsection{Effects of number of compressions}

Fig. 2 shows stress-strain curves from compression in the ED and TD. A strain of 0.02-0.05 was generated by repeated alternate compression, so the stress-strain curves were drawn from a strain of $0.02-0.05$. Alternate compression was repeated 10 times at 
room temperature, giving a total applied strain of 1.67. Mg alloys with large grain sizes often exhibit low ductility. However, the current $\mathrm{Mg}$ specimen with a large grain size of $350 \mu \mathrm{m}$ was not fractured even after 10 alternate compressions, despite the large applied strain. All the stress-strain curves exhibited concave-downward profiles, suggesting that $\{10 \overline{1} 2\}$ twinning occurred during ED compression, and detwinning during TD compression. It is noted that the flow stress decreased with increasing compression number for both ED and TD compression, except for the initial ED compression.

Fig. 3 shows a SEM image of the specimen after the 20TD compression. $\{10 \overline{1} 1\}$ and $\{10 \overline{1} 2\}$ twins are shown by yellow and white arrows, respectively. This is because the basal plane was reoriented by $54^{\circ}$ around the $\langle 1 \overline{2} 10\rangle$ axis for the $\{10 \overline{1} 1\}$ twin, and by $82^{\circ}$ around the $\langle 1 \overline{2} 10\rangle$ axis for the $\{10 \overline{1} 2\}$ twin. The $\{10 \overline{1} 1\}$ twins were connected by $\{10 \overline{1} 2\}$ twins [29]. The relationship between the twin area fraction and the number of compressions is shown in Fig. 4. Approximately half of the twin area fraction of the specimen after the 20TD compression had formed after the 2TD compression, and the twin area fraction increased with increasing compression number. This was mainly because no $\{10 \overline{1} 1\}$ detwinning occurred during alternate compression in two orthogonal directions, in contrast to $\{10 \overline{1} 2\}$ detwinning [34].

(0002) basal pole figures of the specimens after the 3ED, the 4TD, the 19ED and the 20TD compression are shown in Fig. 5. Figs. 5(a) and (c) show that the basal texture was reoriented by $\sim 90^{\circ}$, when the specimen was compressed in the ED. This indicates that $\{10 \overline{1} 2\}$ twinning occurred significantly during ED compression. Figs. 5(b) and (d) shows that the basal planes reoriented upon compression in the TD. This was due to $\{10 \overline{1} 2\}$ (de)twinning during TD compression. $\{10 \overline{1} 2\}$ twinning and $\{10 \overline{1} 2\}$ detwinning are indistinguishable during TD compression. The maximum basal texture 
intensity decreased with increasing compression number, which was probably related to the formation of $\{10 \overline{1} 1\}$ twins [35]. The flow stresses decreased with increasing compression number, despite the twin area fraction increasing with increasing compression number. The decreased flow stress with increasing compression number is thought to be related to the reduced basal texture intensity.

\section{$3.2\{10 \overline{1} 1\}-\{10 \overline{1} 2\}$ double twin}

Fig. 6 shows a SEM image of the specimen after the 19ED compression. Parallel structures were observed both outside and inside the $\{10 \overline{1} 1\}$ twin, and were oriented in a specific direction. The parallel structures within the $\{10 \overline{1} 1\}$ twin were $\{10 \overline{1} 1\}-\{10 \overline{1} 2\}$ double twins.

$\{10 \overline{1} 1\}-\{10 \overline{1} 2\}$ double twins are classified into four types, according to the geometric relationship between the primary $\{10 \overline{1} 1\}$ and secondary $\{10 \overline{1} 2\}$ twin planes [17]. The most commonly observed type 1 double twin is reoriented by $\langle\overline{2} 110\rangle$ $38^{\circ}$ from the matrix [12-16]. TEM observations have revealed $\{10 \overline{1} 2\}$ habit planes sharply inclined against $\{10 \overline{1} 1\}$ habit planes for type 1 double twins [11]. However, Fig. 6 shows that the habit plane of the $\{10 \overline{1} 2\}$ twin was almost perpendicular to that of the $\{10 \overline{1} 1\}$ twin in the alternately-compressed specimen. This suggests that the variant of the double twin generated during alternate compression differed from that generated during simple deformation.

It is important to investigate whether ED or TD compression generated the double twin because the origin of double twinning during alternate compression is related to the direction of compression. Fig. 7(a) shows the microstructure of the specimen after the 2TD compression. The twins found in Fig. 7(a) were $\{10 \overline{1} 1\}$ twins. Fig. 7(b) shows the 
microstructure of the specimen compressed to $3.5 \%$ strain in the $3 \mathrm{ED}$ after the 2TD compression. In the specimen after the 2TD compression, white areas outside $\{10 \overline{1} 1\}$ twins were matrixes because $\{10 \overline{1} 2\}$ (de)twinning occurred during TD compression. Areas inside $\{10 \overline{1} 1\}$ twins were also white. Although double twins were observed in $\{10 \overline{1} 1\}$ twins, the number of double twins were very few. On the other hand, white and brown areas were observed outside $\{10 \overline{1} 1\}$ twins in the specimen compressed in the ED, as shown in Fig. 7(b). The white and brown areas were matrixes and $\{10 \overline{1} 2\}$ twins, respectively, because $\{10 \overline{1} 2\}$ twinning partially occurred during ED compression to a strain of $3.5 \%$. Many striped white and brown areas were observed inside $\{10 \overline{1} 1\}$ twins in the specimen compressed in the ED. Thus, many double twins were formed during ED compression, but barely during TD compression. An inspection of Fig. 7(b) shows that double twins were located adjacent to the brown areas outside the $\{10 \overline{1} 1\}$ twins. It is therefore suggested that the double twins were related to $\{10 \overline{1} 2\}$ twinning outside $\{10 \overline{1} 1\}$ twins.

Fig. 8 shows the change in c-axis direction during alternate compression in two orthogonal directions, assuming that the crystal lattices are rotated about the $\langle\overline{2} 110\rangle$ axis. The c-axis is oriented perpendicular to the ED before ED compression (Fig. 8(i)), so $\{10 \overline{1} 2\}$ twinning occurs during ED compression. $\{10 \overline{1} 2\}$ twins grow quickly and cover most grains $[4,36,37]$, so the whole matrix rotate by $86.2^{\circ}$ to form a new matrix (Fig. 8(ii)). The orientation of the rotated matrix favors $\{10 \overline{1} 1\}$ twinning upon ED compression (Fig. 8(iii)). \{10 $\overline{1} 2\}$ (de)twinning occurs during subsequent TD compression, because the orientation of the new matrix favors $\{10 \overline{1} 2\}$ twinning. Thus, a second new matrix is formed (Fig. 8(iv)). $\{10 \overline{1} 1\}$ twins generated during ED 
compression remain during TD compression, because no $\{10 \overline{1} 1\}$ detwinning occurs during TD compression (Fig. 8(iv)). Fig. 8(v) shows the change in crystal orientation during the second ED compression. $\{10 \overline{1} 2\}$ twinning occurs both outside and inside the $\{10 \overline{1} 1\}$ twin, so $\{10 \overline{1} 1\}-\{10 \overline{1} 2\}$ double twins are formed during ED compression. Actually, the c-axes of matrixes are distributed in various directions before ED compression. However, they are vertical to the ED before ED compression. Hence, they are distributed in almost the same direction after ED compression because matrixes rotate by about $90^{\circ}$ by $\{10 \overline{1} 2\}$ twinning during ED compression. Thus, evolution of twins during TD compression can occur in the same manner.

Misorientation relationships between the matrix and twin variants are shown in Fig. 9. For simple compression, a $\{10 \overline{1} 2\}$ twin formed in a $\{10 \overline{1} 1\}$ twin is a secondary twin, as shown in Fig. 9(a). In this case, the matrix is the new matrix in Fig. 8(iii). For alternate compression in two orthogonal directions, a $\{10 \overline{1} 2\}$ twin formed in a $\{10 \overline{1} 1\}$ twin is a tertiary twin, as shown in Fig. 9(b). In this case, the matrix is the second new matrix in Fig. 8(v). Consequently, the misorientation relationships of alternately-compressed specimens differ from those of simple compressed specimens.

EBSD was used to investigate the crystal orientations of the specimen compressed to $3.5 \%$ strain in the $3 \mathrm{ED}$, after the $2 \mathrm{TD}$ compression, and to estimate the type of tertiary $\{10 \overline{1} 2\}$ twin. Different EBSD results are shown in Figs. 10 and 11. In Fig. 10, the matrix (second new matrix) was the red area of A or the purple area of B. The striped region consisting of $\mathrm{D}$ and $\mathrm{D}$ ' was located adjacent to B. Besides, the misorientation between $\mathrm{A}$ and $\mathrm{C}\left(=<1 \overline{2} 10>40.3^{\circ}\right)$ corresponded to that between the matrix and secondary $\{10 \overline{1} 1\}$ twin $\left(=<1 \overline{2} 10>37.6^{\circ}\right)$ in Fig. 9(b). These facts indicate that A was the matrix, $B$ was the $\{10 \overline{1} 2\}$ twin, $C$ was the $\{10 \overline{1} 1\}$ twin, and $D$ and $D^{\prime}$ 
were double twins. The misorientation between A and D was $<13 \overline{9} \overline{4} \overline{4}>80.2^{\circ}$, and that between A and D' was $<3 \overline{2} \overline{1} \overline{1}>80.1^{\circ}$. Thus, the double twins in Fig. 9 were type 3 tertiary $\{10 \overline{1} 2\}$ twins $\left(=<6 \overline{28} 22 \overline{9}>80.2^{\circ}\right)$. Another EBSD result is shown in Fig. 11. A similar analysis indicated that $\mathrm{E}$ (red) was the matrix, F (blue) was the $\{10 \overline{1} 2\}$ twin, $\mathrm{G}$ (pink) was the $\{10 \overline{1} 1\}$ twin and $\mathrm{H}$ (green) was the double twin. The misorientation between $\mathrm{E}$ and $\mathrm{H}$ was $<\overline{3} \overline{16} 197>75.0^{\circ}$. Thus, $\mathrm{H}$ was a type 4 double twin $(=<1 \overline{6} 5 \overline{2}>$ $\left.73.6^{\circ}\right)$. Double twins generated during alternate compression in two orthogonal directions were of types 3 and 4, rather than type 1 .

In the present study, alternate compression in two orthogonal directions was carried out at room temperature. If alternate compression in two orthogonal directions is performed at high temperature, the origin of double twinning may be changed because non-basal slips occur easily at high temperature. Besides, alternate compression at room temperature was designed to allow the investigation of room temperature recrystallization. It was difficult to obtain clear Kikuchi patterns during EBSD measurements, which limited the number of double twins that could be investigated. Of the 13 observed double twins, three were type 3 and 10 were type 4 . The limited number of available double twins was insufficient to conclude that type 1 and 2 twins did not occur. However, the fact that all the double twins investigated were the types 3 and 4 twins indicates that the types 3 and 4 double twins are generated more easily than the types 1 and 2 double twins during alternate compression at room temperature.

A and $\mathrm{C}$ shared a common $<\overline{2} 110>$ axis, marked with a red dashed circle in Fig. 12(a). This means that the second new matrix generated by TD compression and the $\{10 \overline{1} 1\}$ twin formed from the new matrix were rotated around the same $<\overline{2} 110>$ axis, 
and that possible variant of $\{10 \overline{1} 1\}$ twin was only one for the misorientation relationship between the second new matrix and the $\{10 \overline{1} 1\}$ twin. The same trend was obtained for $\mathrm{E}$ and $\mathrm{G}$, as shown in Fig. 13(a). Hence, in the analyses of EBSD measurements, misorientation relationships were calculated for only one variant of the $\{10 \overline{1} 1\}$ twins. Fig. 12(b) shows poles of $\{10 \overline{1} 2\}$ twin systems with six variants for $C$ in Fig. 10, where $C$ is the $\{10 \overline{1} 1\}$ twin. The $\{10 \overline{1} 2\}$ twinning poles of $D$ are superimposed in the figure, where $D$ is the $\{10 \overline{1} 1\}-\{10 \overline{1} 2\}$ twin. The number of twinning poles indicates the type of double twins, which is determined by the geometric relationship with the pole of the active $\{10 \overline{1} 1\}$ twin. The $\{10 \overline{1} 2\}$ twinning poles of $\mathrm{C}$ and $\mathrm{D}$ were overlapped at 3 , as shown by the red dashed circle. This indicates that the activated $\{10 \overline{1} 2\}$ twin was type 3', and corresponded to the result in Fig. 10. Fig. 12(c) shows the SF values of $\{10 \overline{1} 2\}$ twin systems with six variants for $\mathrm{C}$, where the loading direction is parallel to the ED because double twins are generated during compression in the ED. The negative SF value in Fig. 12(c) indicates the compressive direction. In this figure, the activated twinning system of the type 3' variant is marked with a red dashed circle. The SF values for the type $1-4$ twins for $C$ are summarized in Table 1. The type 3' twin exhibited the largest SF. The result for G in Fig. 11 is shown in Fig. 13. In this case, the activated $\{10 \overline{1} 2\}$ twin was type 4, from the overlap of the poles of $\mathrm{G}$ and $\mathrm{H}$. This corresponded to the result in Fig. 11. The SF values for the type 1-4 twins for G are summarized in Table 2 . The SF for the type 4 twin was large, though not the largest. Thus, the activated tertiary $\{10 \overline{1} 2\}$ twins were related to large SF values.

The previous works [11-17] on simple compressive or tensile deformation showed that the variant selection of secondary $\{10 \overline{1} 2\}$ twin depended on the strain 
accommodation and non-basal slip, resulting in non-Schmid behavior. Thus, the type of activated $\{10 \overline{1} 2\}$ twin in a double twin could not be explained by the SF for simple compressive or tensile deformation. The medium surrounding twins affects the stress development [38]. Luo et al. showed that the variant selection depended on the external strain accommodation [16]. For alternate compression in two orthogonal directions, $\{10 \overline{1} 2\}$ twinning outside the $\{10 \overline{1} 1\}$ twin can contribute to the external strain accommodation. Hence, it is worthwhile to investigate $\{10 \overline{1} 2\}$ twins outside the $\{10 \overline{1} 1\}$ twin. Fig. 14(a) shows a SEM image of the area surrounding $\{10 \overline{1} 1\}-\{10 \overline{1} 2\}$ double twins, and Fig. 14(b) shows a corresponding schematic. It can be seen that the $\{10 \overline{1} 2\}$ twin outside the $\{10 \overline{1} 1\}$ twin transferred to a neighboring matrix region through the $\{10 \overline{1} 1\}$ twin, thus forming double twins. Thus, the $\{10 \overline{1} 2\}$ twinning outside the $\{10 \overline{1} 1\}$ twins not only contributes to the external strain accommodation, but also induces $\{10 \overline{1} 2\}$ twinning inside the $\{10 \overline{1} 1\}$ twin. Hence, the geometric relationship between the $\{10 \overline{1} 2\}$ twins outside and inside the $\{10 \overline{1} 1\}$ twin is important for the variant selection of tertiary $\{10 \overline{1} 2\}$ twin. To date, geometric relationships between active slip systems in different grains have been studied [19,20,30-33,39]. Wang et al. found that paired twinning systems nucleated at grain boundaries in Ti had a large GCF [31,32]. Xin et al. showed that long $\{10 \overline{1} 2\}$ twins across the grain boundary in Mg had a large GCF [33]. Also, Beyerlein et al. showed from an analysis of twin pairs joined at a boundary that grain boundary misorientation angle strongly influences twin nucleation and growth $[19,20]$. Thus, it is worth investigating the GCF values and geometric relationship between $\{10 \overline{1} 2\}$ twins outside and inside the $\{10 \overline{1} 1\}$ twin. The GCF values of $\{10 \overline{1} 2\}$ twin systems with six variants are shown in Fig. 12(d) for C of Fig. 10, and in Fig. 13(d) for G of Fig. 11. 
The activated twinning system is marked with a red dashed circle. The GCF values for the type 1-4 twins are summarized in Tables 1 and 2 for $\mathrm{C}$ and G, respectively. In both cases, large GCF values were obtained for the active $\{10 \overline{1} 2\}$ twinning systems. The SF of the type 3' twin was the largest for C, but the activated twin was not type 3'. This is because the GCF of the type 3' twin was very low, as shown in Table 2. Strain accommodation was critical for generating double twins during simple deformation [13]. Hence, type $1\{10 \overline{1} 2\}$ twins are most commonly generated, despite their low SF. However, in the case of alternate compression, the geometric compatibility between $\{10 \overline{1} 2\}$ twins inside and outside the $\{10 \overline{1} 1\}$ twin is the determinant for the variant selection. This is because $\{10 \overline{1} 2\}$ twinning outside the $\{10 \overline{1} 1\}$ twin induces $\{10 \overline{1} 2\}$ twinning inside the $\{10 \overline{1} 1\}$ twin. However, as shown in Table 1 , although the GCF for the type 4 variant was the largest for $\mathrm{C}$, the type 4 variant twin was not generated. This is because of the low SF for the type 4 variant. Thus, both SF and GCF were critical for the variant selection of double twins generated during alternate compression in two orthogonal directions.

One of interesting results in the present work is that double twins were generated during compression in the ED, but barely in the TD. SF values of $\{10 \overline{1} 2\}$ twin systems with six C variants for loading parallel to the TD were calculated. The results in Table 3 show that all SF values were positive. A positive SF indicates that twinning could occur during tensile deformation in the TD. Thus, tertiary $\{10 \overline{1} 2\}$ twins were barely generated during compression in the TD.

Another interesting result was that $\{10 \overline{1} 2\}$ twins did not necessarily pass thorough $\{10 \overline{1} 1\}$ twin boundaries, and striped areas were formed inside $\{10 \overline{1} 1\}$ twins. Recently, Yu et al. investigated $\{10 \overline{1} 2\}-\{10 \overline{1} 2\}$ interactions and they showed that twin 
transmission occurs under special loading conditions $[40,41] .\{10 \overline{1} 1\}$ twin boundaries tend to absorb dislocations [42]. Hence, all dislocations on $\{10 \overline{1} 2\}$ cannot pass through $\{10 \overline{1} 1\}$ twin boundaries. Actually, $\{10 \overline{1} 1\}$ twin boundaries give rise to the intense strain hardening [43], indicating that $\{10 \overline{1} 1\}$ twin boundaries are tough barriers for passing of dislocations. Hard passing of dislocations leads to the partial formation of $\{10 \overline{1} 2\}$ twins in the $\{10 \overline{1} 1\}$ twin. Hence, a large SF for formation of double twins is suggested to be related to the hard passing.

\subsection{Room temperature recrystallization}

Fig. 15 shows a SEM image of the $\{10 \overline{1} 1\}$ twin in the specimen after the 20TD compression. Complex fine structures were observed in the specimen. These structures differed from twin structures because their boundaries were oriented randomly. The complex fine structures were occasionally observed in the specimen after the 20TD compression. Fig. 16 shows a TEM image of the complex structures in the $\{10 \overline{1} 1\}$ twin. Fine recrystallized grains of size $<1 \mu \mathrm{m}$ were observed. It is noted that dynamic recrystallization occurred at room temperature in the $\{10 \overline{1} 1\}$ twin during alternate compression in two orthogonal directions. Room temperature recrystallization or recovery in $\mathrm{Mg}$ has been previously observed [44-48]. Koike et al. showed that dynamic recovery occurred in twins in AZ31 Mg elongated to $16 \%$ at room temperature [48]. Liang et al. performed cold extrusion of AZ31 Mg alloy, and showed that dynamic recrystallization during cold extrusion was related to the heat generated during extrusion [47]. In the present work, the compressive strain rate was sufficiently low that processing heat was not responsible for room temperature recrystallization. The present specimens were not hot after compression and they were handled by bare skin. 
Dynamic recrystallization in $\mathrm{Mg}$ is related to continuous recrystallization, namely, a low angle boundary such as a sub-grain wall gradually converts to a high angle boundary by the absorption of dislocations. Twin boundaries often affect recrystallization in $\mathrm{Mg}$ [49-51], so may transform to high angle boundaries. Galiyev and Kaibyshev [45] showed that a full grained structure was obtained in ZK60 Mg alloy under a large strain at room temperature. This indicates that the large strain induces room temperature recrystallization. Double twins provided fracture sites in the current alternately-compressed specimen [29], indicating that an intense strain was generated around double twins during alternate compression. Therefore, an intense strain around double twins may stimulate room temperature recrystallization.

Numerous double twins were generated during alternate compression in two orthogonal directions, but the specimen was not fractured even after 10 alternate compressions at room temperature. Room temperature recrystallization can relax the stress concentration generated at double twins. Therefore, the high ductility of alternately-compressed specimens likely resulted from room temperature recrystallization.

\section{Conclusions}

Extruded AZ31 Mg alloy was alternately compressed in the ED and subsequently in the TD at room temperature. The microstructures of the compressed specimens were investigated.

(1) The specimen was not fractured even after 10 alternate compressions. $\{10 \overline{1} 2\}$

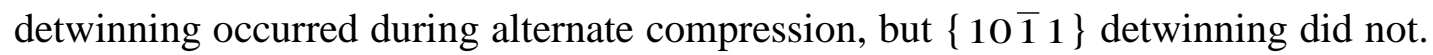
Consequently, the twin area fraction increased with increasing compression number. 
(2) $\{10 \overline{1} 1\}-\{10 \overline{1} 2\}$ double twins were generated during ED compression, but barely during TD compression. This was explained by the SF.

(3) Types 3 and 4 double twins were generated during alternate compression in two orthogonal directions, which did not correspond to the result for deformation in one direction, where type 1 double twins were most commonly formed.

(4) The Schmid factor (SF) and geometric compatibility factor (GCF) were large for the activated twinning systems. The SF and GCF strongly affected the formation of double twins during alternate compression in two orthogonal directions.

(5) $\{10 \overline{1} 2\}$ twinning outside the $\{10 \overline{1} 1\}$ twin induced $\{10 \overline{1} 2\}$ twinning inside the $\{10 \overline{1} 1\}$ twin, thus generating $\{10 \overline{1} 1\}-\{10 \overline{1} 2\}$ double twins. Hence, the geometric compatibility between $\{10 \overline{1} 2\}$ twins inside and outside the $\{10 \overline{1} 1\}$ twin was determinant for the variation selection. Also, $\{10 \overline{1} 1\}$ twin boundaries hindered to transmission of dislocations, which required a large SF.

(6) Fine recrystallized grains were observed in the $\{10 \overline{1} 1\}$ twin for the specimen after the 20TD compression. Thus, dynamic recrystallization occurred at room temperature. Room temperature recrystallization was likely responsible for the high ductility of the alternately-compressed specimens.

\section{Acknowledgments}

This study was financially supported by JSPS Grant-in-Aid for Scientific Research (B) 26289257. 


\section{References}

[1] M.H. Yoo, Metall. Trans. A 12 (1981) p.409.

[2] J. Koike, Metall. Mater. Trans. A 36 (2005) p.1689.

[3] M.R. Barnett, Mater. Sci. Eng. A 464 (2007) p.1.

[4] L. Jiang, J.J. Jonas, R.K. Mishra, A.A. Luo, A.K. Sachdev and S.Godet, Acta Mater. 55 (2007) p.3899.

[5] M.R. Barnett, Mater. Sci. Eng. A 464 (2007) p.8.

[6] H. El Kadiri, J. Kapil, A.L. Oppedal, Jr L.G. Hector, S.R. Agnew, M. Cherkaoui and S.C. Vogal, Acta Mater. 61 (2013) p.3549.

[7] J. Wang, I.J. Beyerlein, J.P. Hirth and C.N. Tomé, Acta Mater. 59 (2011) p.3990.

[8] J. Wang, I.J. Beyerlein and J.P. Hirth, Modelling Simul. Mater. Sci. Eng. 20 (2012) p.024001.

[9] B.C. Wonsiewicz and W.A. Backofen, AIME Trans. 239 (1967) p.1422.

[10] D. Ando, J. Koike and Y. Sutou, Acta Mater. 58 (2010) p.4316.

[11] P. Cizek and M.R. Barnett, Scr. Mater. 59 (2008) p.959.

[12] M.R. Barnett, Z. Keshavarz, A.G. Beer and X. Ma, Acta Mater. 56 (2008) p.5.

[13] É. Martin, L. Capolungo, L. Jiang and J.J. Jonas, Acta Mater. 58 (2010) p.3970.

[14] J.J. Jonas, S. Mu, T. Al-Samman, G. Gottstein, L. Jiang and É. Martin, Acta Mater. 59 (2011) p.2046.

[15] S. Mu, J.J. Jonas and G. Gottstein, Acta Mater. 60 (2012) p.2043.

[16] J.R. Luo, A. Godfrey, W. Liu and Q. Liu, Acta Mater. 60 (2012) p.1986.

[17] I.J. Beyerlein, J. Wang, M.R. Barnett and C.N. Tomé, Proc. R. Soc. A 468 (2012) p.1496. 
[18] R. Xin, M. Wang, X. Huang, C. Guo and Q. Liu, Mater. Sci. Eng. A 596 (2014) p.41.

[19] I.J. Beyerlein, L. Capolungo, P.E. Marshall, R.J. McCabe and C.N. Tomé, Phi. Mag. 90 (2010) p.2161.

[20] I.J. Beyerlein, R.J. McCabe and C.N. Tomé, J. Mech. Phys. Sol. 59 (2011) p.988.

[21] Y.N. Wang and J.C. Huang, Acta Mater. 55 (2007) p.897.

[22] S. Kleiner and P.J. Uggowitzer, Mater. Sci. Eng. A 379 (2004) p.258.

[23] X.Y. Lou, M. Li, R.K. Boger, S.R. Agnew and R.H. Wagoner, Int. J. Plast. 23 (2007) p.44.

[24] L. Wu, A. Jain, D.W. Brown, G.M. Stoica, S.R. Agnew, B. Clausen, D.E. Fielden and P.K. Liaw, Acta Mater. 56 (2008) p.688.

[25] F. Zhang, M. Hao, F.C. Wang, C.W. Tan, X.D. Yu, H.L. Ma, N. Cai, Scr. Mater. 67 (2012) p.951.

[26] D. Sarker, D.L. Chen, Scr. Mater. 67 (2012) p.165.

[27] J. Wang, L. Liu, C.N. Tomé, S.X. Mao, S.K. Gong, Mater. Res. Lett. 1 (2013) p.81.

[28] Q. Yu, J. Zhang and Y. Jiang, Phi. Mag. Lett. 91 (2011) p.757.

[29] H. Kwon, M. Mabuchi and Y. Chino, Mater. Trans. 55 (2014) p.739.

[30] J. Luster and M.A. Morris, Metall. Mater. Trans. A 26 (1995) p.1745.

[31] L. Wang, Y. Yang, P. Eisenlohr, T.R. Bieler, M.A. Crimp and D.E. Mason, Metall. Mater. Trans. A 41 (2010) p.421.

[32] L. Wang, P. Eisenlohr, Y. Yang, T.R. Bieler and M.A. Crimp, Scr. Mater. 63 (2010) p.827.

[33] R. Xin, C. Guo, Z. Xu, G. Liu, X. Huang and Q. Liu, Scr. Mater. 74 (2014) p.96. 
[34] M. Yuasa, M. Hayashi, M. Mabuchi and Y. Chino, J. Phys.: Condense. Matter 26 (2014) p.015003.

[35] Z. Zhang, P. Cizek and M. Barnett, Scr. Mater. 67 (2012) p.1015.

[36] Y. Xin, M. Wang, Z. Zeng, G. Huang and Q. Liu, Scr. Mater. 64 (2011) p.986.

[37] Y. Xin, J. Jiang, A. Chapuis, M. Wang and Q. Liu, Mater. Sci. Eng. A 532 (2012) p.50.

[38] C.C. Aydiner, J.V. Bernier, B. Clausen, U. Lienert and C.N. Tomé and D.W. Brown, Phys. Rev. B 80 (2009) p.024113.

[39] N. Bozzolo, L. Chan and A.D. Rollett, J. Appl. Cryst. 43 (2010) 596.

[40] Q. Yu, J. Wang, Y. Jiang, R.J. McCabe, N. Li and C.N. Tomé, Acta Mater. 77 (2014) p.28.

[41] Q. Yu, J. Wang, Y. Jiang, R.J. McCabe and C.N. Tomé, Mater. Res. Lett. 2 (2014) p.82.

[42] M. Yuasa, K. Masunaga, M. Mabuchi and Y. Chino, Phi. Mag. 94 (2014) p.285.

[43] M. Knezevic, A. Levinson, R. Harris, R.K. Mishra, R.D. Doherty and S.R. Kalidindi, Acta Mater. 58 (2010) p.6230.

[44] R. Kaibyshev and O. Sitdikov, Z. Metallkd. 85 (1994) p.738.

[45] A. Galiyev and R. Kaibyshev, Mater. Trans. 42 (2001) p.1190.

[46] R.Z. Abdulov, R.Z. Valiev and N.A. Krasilnikov, J. Mater. Sci. Lett. 9 (1990) p.1445.

[47] S.J. Liang, Z.Y. Liu and E.D. Wang, Mater. Lett. 62 (2008) p.4009.

[48] J. Koike, T. Kobayashi, T. Mukai, H. Watanabe, M. Suzuki, K. Maruyama and K. Higashi, Acta Mater. 51 (2003) p.2055.

[49] R.O. Kaibyshev and O.S. Sitdikov, Phys. Met. Metallo. 89 (2000) p.384. 
[50] O. Sitdikov and R. Kaibyshev, Mater. Trans. 42 (2001) p.1928.

[51] S. Yi, I. Schestakow and S. Zaefferer, Mater. Sci. Eng. A 516 (2009) p.58. 
Table 1. SF and GCF values for type 1-4 twins for C in Fig. 10. The loading direction is parallel to the ED. Negative SF values indicate the compressive direction.

\begin{tabular}{|l|l|l|l|l|l|l|}
\hline $\begin{array}{l}\text { Type of double } \\
\text { twin }\end{array}$ & Type1 & Type2 & Type3 & Type3* & Type4 & Type4' \\
\hline Schmid factor & -0.206 & -0.188 & -0.016 & -0.445 & -0.024 & -0.419 \\
\hline $\begin{array}{l}\text { Geometric } \\
\text { compatibility } \\
\text { factor }\end{array}$ & 0.314 & 0.625 & 0.098 & 0.825 & 0.903 & 0.239 \\
\hline
\end{tabular}


Table 2. SF and GCF values for type 1-4 twins for G in Fig. 11. The loading direction is parallel to the ED. Positive and negative SF values indicate the tensile and compressive directions, respectively.

\begin{tabular}{|l|l|l|l|l|l|l|}
\hline $\begin{array}{l}\text { Type of double } \\
\text { twin }\end{array}$ & Type1 & Type2 & Type3 & Type3, & Type4* & Type4' \\
\hline Schmid factor & 0.052 & 0.062 & -0.137 & -0.329 & -0.285 & -0.171 \\
\hline $\begin{array}{l}\text { Geometric } \\
\text { compatibility } \\
\text { factor }\end{array}$ & -0.225 & 0.578 & 0.333 & -0.359 & 0.771 & 0.036 \\
\hline
\end{tabular}


Table 3. SF values for type 1-4 twins for $\mathrm{C}$ in Fig. 10. The loading direction is parallel to the TD. Positive SF values indicate the tensile direction.

\begin{tabular}{|l|l|l|l|l|l|l|}
\hline $\begin{array}{l}\text { Type of } \\
\text { double twin }\end{array}$ & variant1 & variant2 & variant3 & variant4 & variant5 & variant6 \\
\hline Schmid factor & 0.239 & 0.218 & 0.33 & 0.189 & 0.163 & 0.325 \\
\hline
\end{tabular}




\section{Figure Captions}

Fig. 1. Microstructure of the extruded AZ31 alloy shown by an (a) LM image and (b) (0002) basal pole figure. The pole figure of a plane parallel to the ED is investigated. The ED and ND are the extrusion and normal directions, respectively.

Fig. 2. Stress-strain curves from alternate compression in the (a) ED and (b) TD. Stress-strain curves are drawn from a strain of $0.02-0.05$ because a strain of $0.02-0.05$ is generated by repeated alternate compression.

Fig. 3. SEM image of the specimen after the 20TD compression. Yellow and white arrows indicate $\{10 \overline{1} 1\}$ and $\{10 \overline{1} 2\}$ twins, respectively.

Fig. 4. Relationship between twin area fraction and number of alternate compressions.

Fig. 5. (0002) basal pole figures of alternatively-compressed specimens after (a) the 3ED compression, (b) the 4TD compression, (c) the 19ED compression and (d) the 20TD compression.

Fig. 6. SEM image of the specimen after the 19ED compression. The parallel structures visible in the long twin are $\{10 \overline{1} 1\}-\{10 \overline{1} 2\}$ double twins.

Fig. 7. LM images of specimens after (a) the $2 \mathrm{TD}$ compression and (b) the 3ED compression to $3.5 \%$ strain after the $2 \mathrm{TD}$ compression. The twins found in (a) are $\{10 \overline{1} 1\}$ twins.

Fig. 8. Schematic of the change in c-axis direction during alternate compression in two orthogonal directions. The c-axis is oriented perpendicular to the ED before ED compression (i). $\{10 \overline{1} 2\}$ twinning occurs during ED compression (ii), and then $\{10 \overline{1} 1\}$ twinning occurs (iii). $\{10 \overline{1} 2\}$ (de)twinning occurs during 
subsequent TD compression, and a second new matrix is formed (iv). $\{10 \overline{1} 2\}$ twinning occurs both outside and inside the $\{10 \overline{1} 1\}$ twin during the second ED compression (v). Details of (i)-(v) are given in the text.

Fig. 9. Misorientation relationships between the matrix and twin for (a) simple compression in one direction and (b) alternate compression in two orthogonal directions. The matrix in (a) is the new matrix in Fig. 8(iii), and the matrix in (b) is the second new matrix in Fig. 8(v).

Fig. 10. EBSD image and crystal orientation of the region around double twins in a specimen compressed to $3.5 \%$ strain in the ED after the 2TD compression. (a) EBSD image, and crystal orientations between (b) A, B, C and D and (c) A, B, C and D'.

Fig. 11. EBSD image and crystal orientations of the region around double twins in a specimen compressed to $3.5 \%$ strain in the ED after the 2TD compression. (a) EBSD image and (b) crystal orientations between E, F, G and H.

Fig. 12. Characterization of $\{10 \overline{1} 2\}$ twin systems with six variants for $C$ in Fig. 10. (a) $(10 \overline{1} 1)$ pole figure, (b) poles of the $(10 \overline{1} 2)$ twinning plane, (c) SF values and (d) GCF values. In (a), the ( $\overline{2} 110$ ) poles of A and C in Fig.10 are overlapped, and the active $\{10 \overline{1} 1\}$ twinning plane is marked with a blue circle. In (b), the $(10 \overline{1} 2)$ twinning poles of D in Fig. 10 are superimposed, and the yellow cross is the pole of the active $\{10 \overline{1} 1\}$ twinning plane. In (c), the loading direction is parallel to the ED, and negative SF values indicate the compressive direction.

Fig. 13. Characterization of $\{10 \overline{1} 2\}$ twin systems with six variants for G in Fig. 11. (a) (10 $\overline{1} 1)$ pole figure, (b) poles of the $(10 \overline{1} 2)$ twinning plane, (c) SF values and 
(d) GCF values. In (a), the ( 2110 ) poles of E and G in Fig. 11 are overlapped, and the active $\{10 \overline{1} 1\}$ twinning plane is marked with a blue circle. In (b), the (10 $\overline{1} 2$ ) twinning poles of $\mathrm{H}$ in Fig. 11 are superimposed, and the yellow cross is the pole of the active $\{10 \overline{1} 1\}$ twinning plane. In (b), the loading direction is parallel to the ED, and negative SF values indicate the compressive direction.

Fig. 14. (a) SEM image and (b) schematic illustration of the microstructure of area surrounding double twins in a specimen compressed to $3.5 \%$ strain in the $3 \mathrm{ED}$, after the 2TD compression.

Fig. 15. SEM image of the $\{10 \overline{1} 1\}$ twin in the specimen after the 20TD compression.

Fig. 16. TEM image of recrystallized fine grains in the $\{10 \overline{1} 1\}$ twin in the specimen after the 20TD compression. 


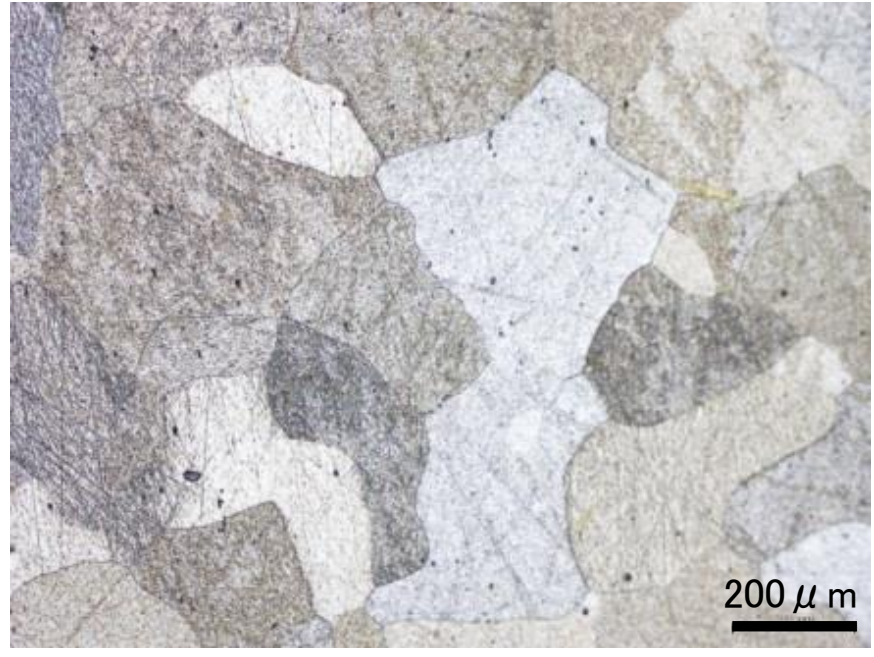

(a)

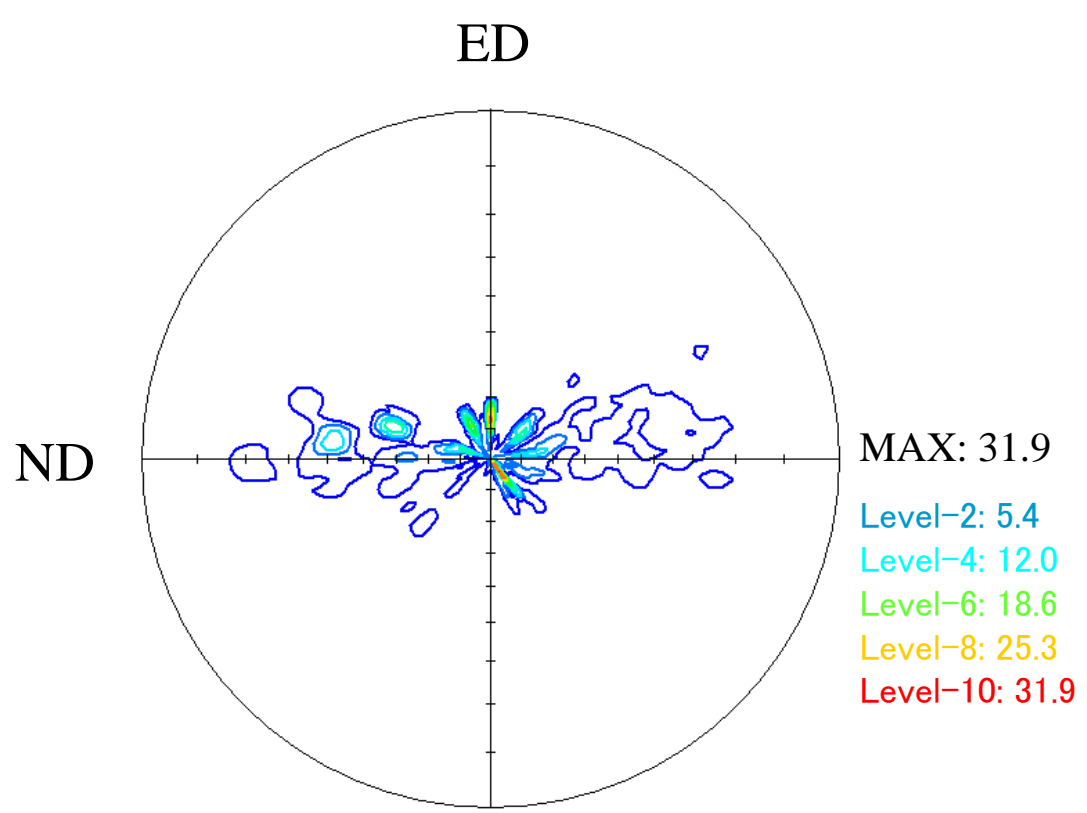

(b)

Figure 1 

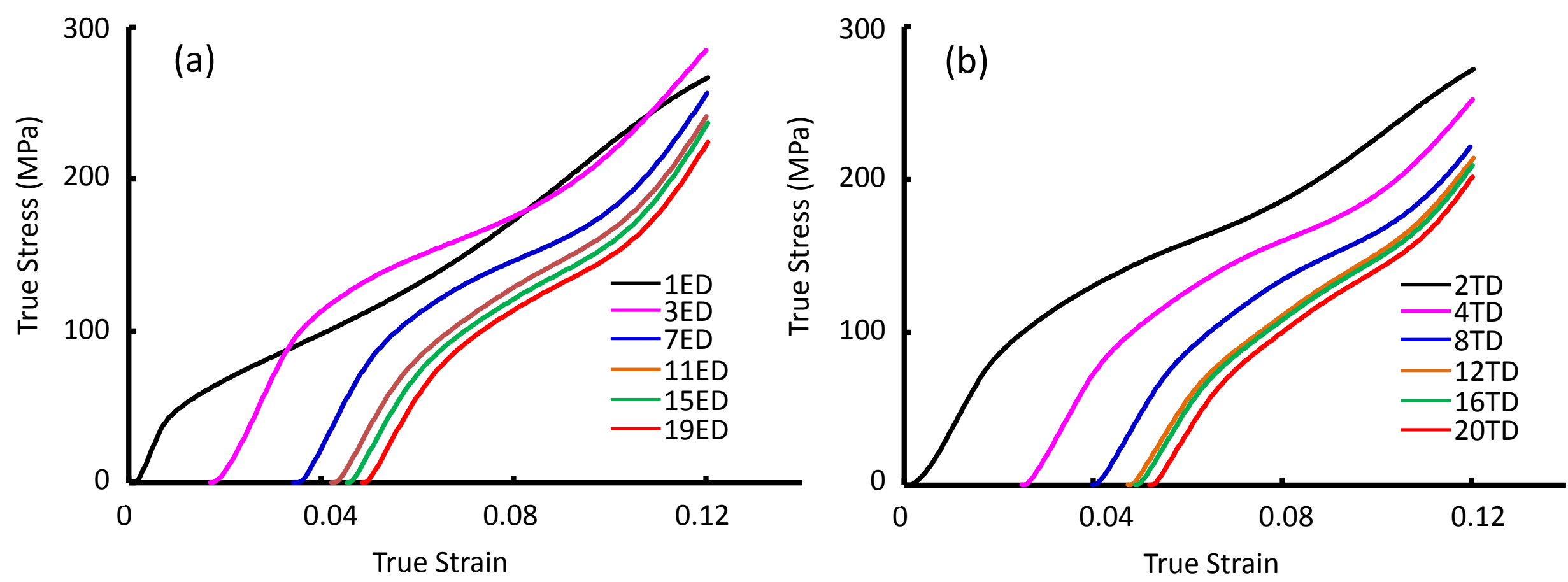

Figure 2 


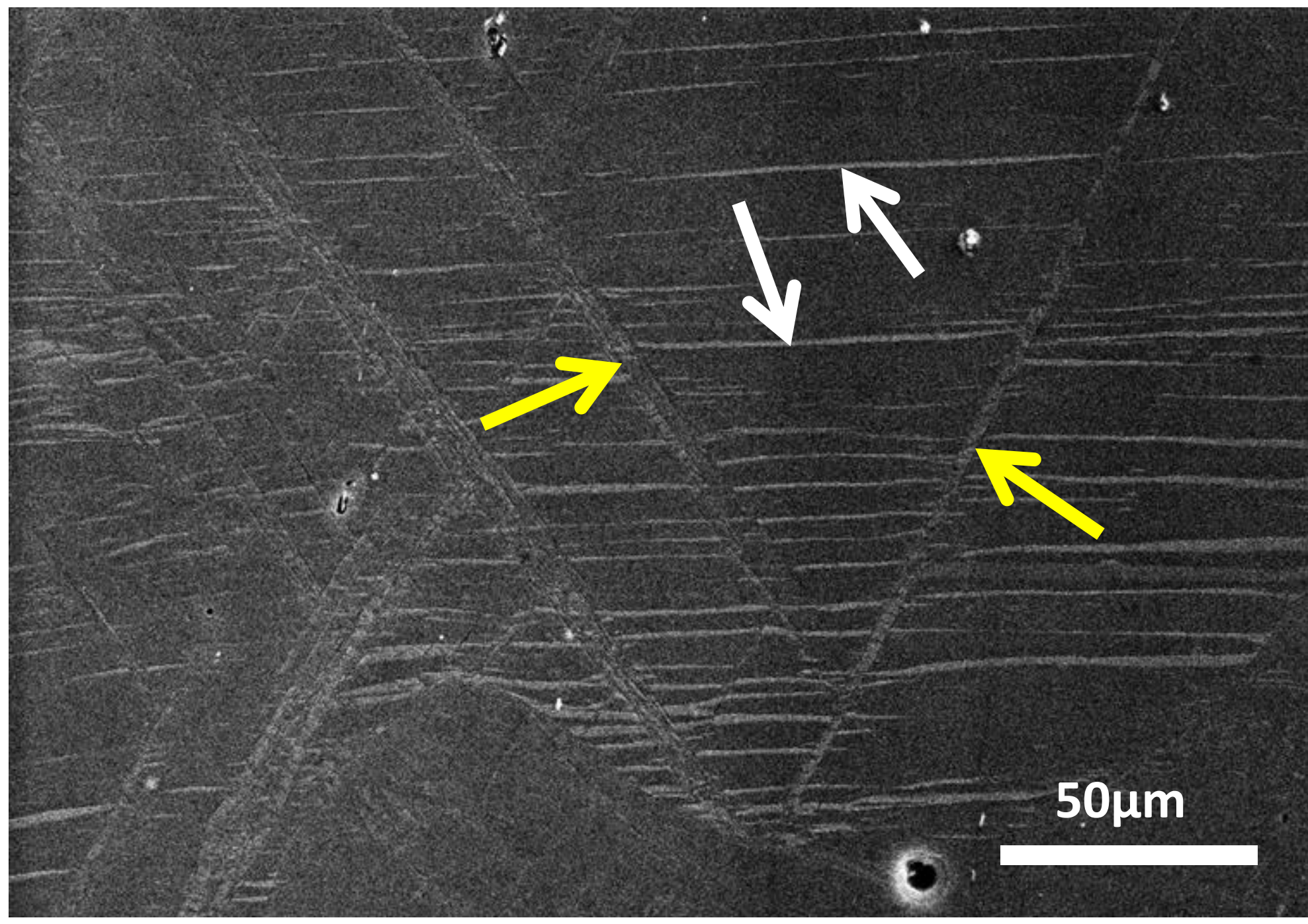

Figure 3 


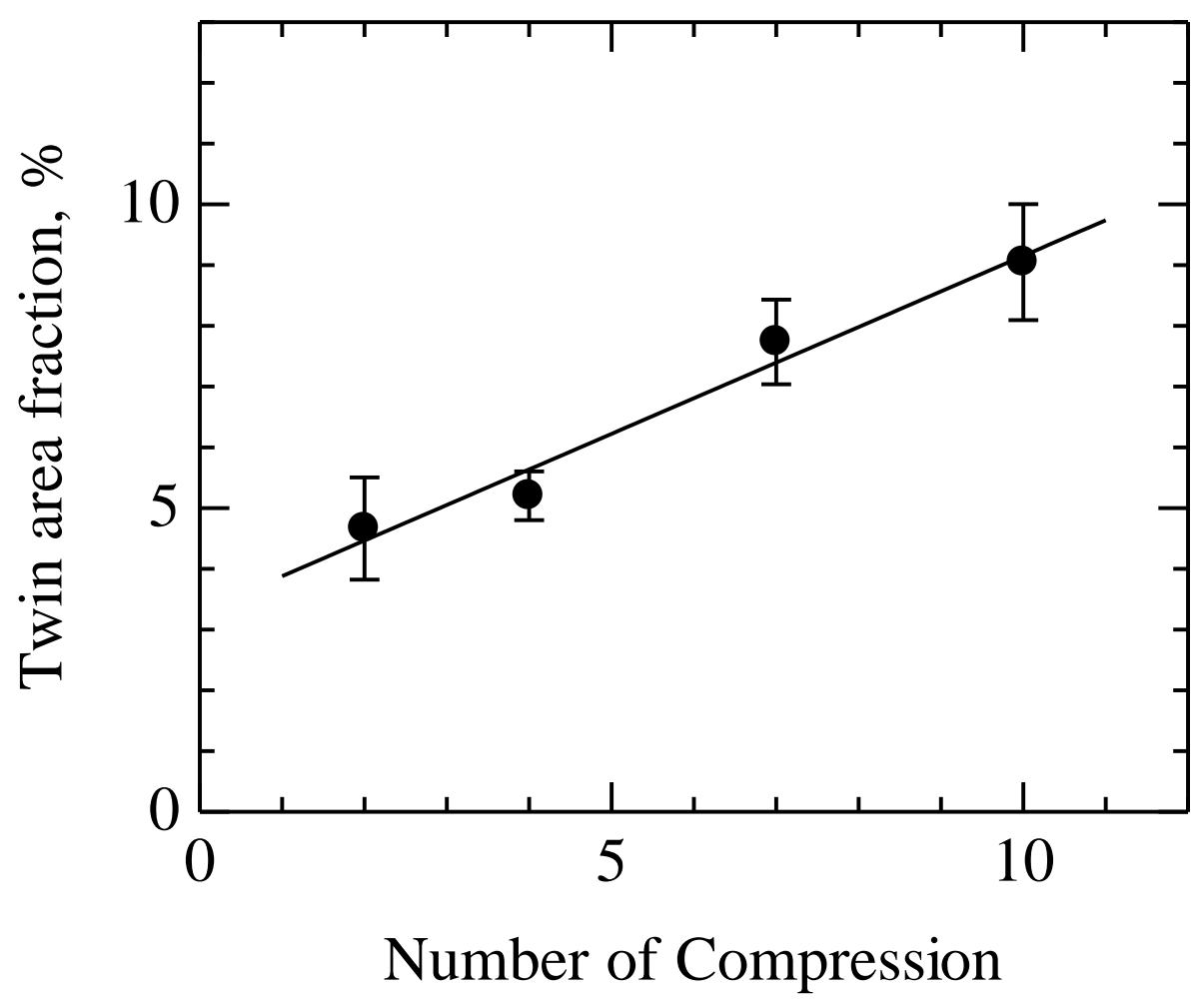

Figure 4 


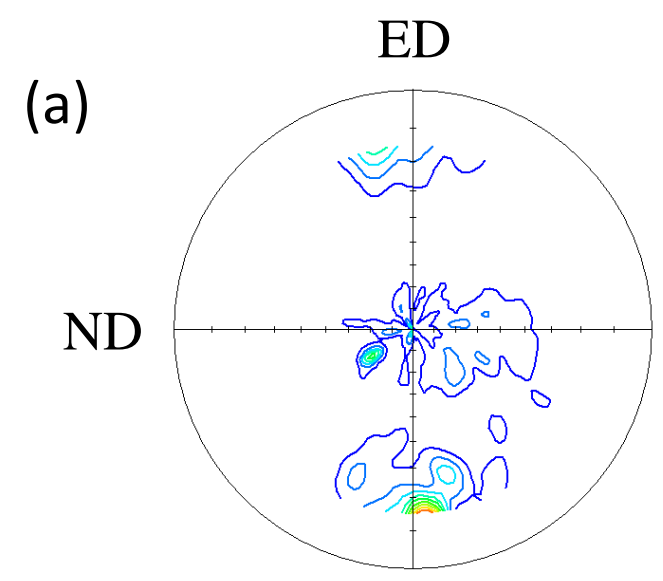

MAX: 13.3

Level-2: 2.7

Level-4: 5.3

Level-6: 7.9

Level-8: 10.7

Level-10: 13.3

(b)

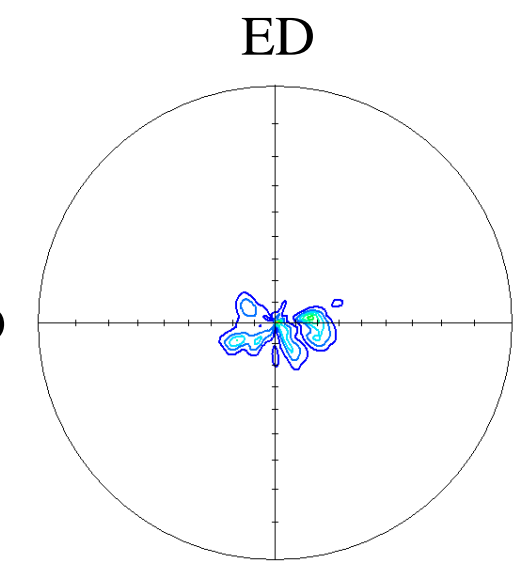

MAX: 43.8

Level-2: 8.8

Level-4: 17.5

Level-6: 26.3

Level-8: 35.1

Level-10: 43.8

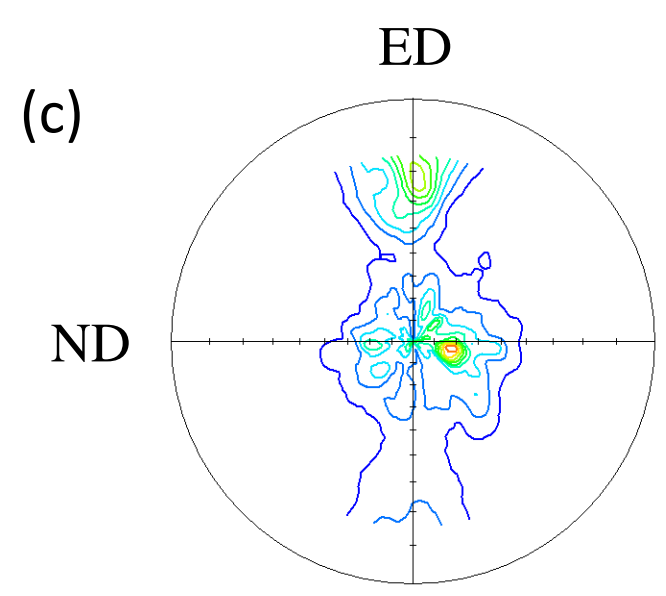

MAX: 7.5

Level-2: 1.5

Level-4: 3.0

Level-6: 4.5

Level-8: 6.0

Level-10: 7.5

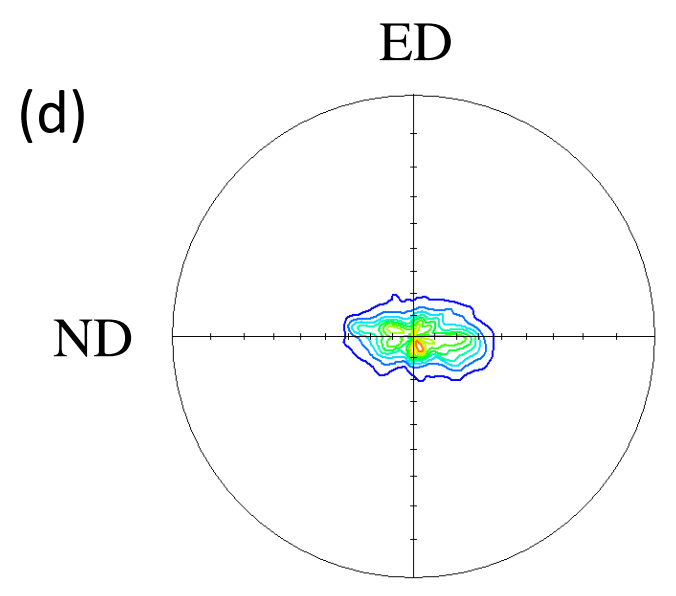

MAX: 16.7

Level-2: 3.3

Level-4: 6.7

Level-6: 10.0

Level-8: 13.4

Level-10: 16.7

Figure 5 


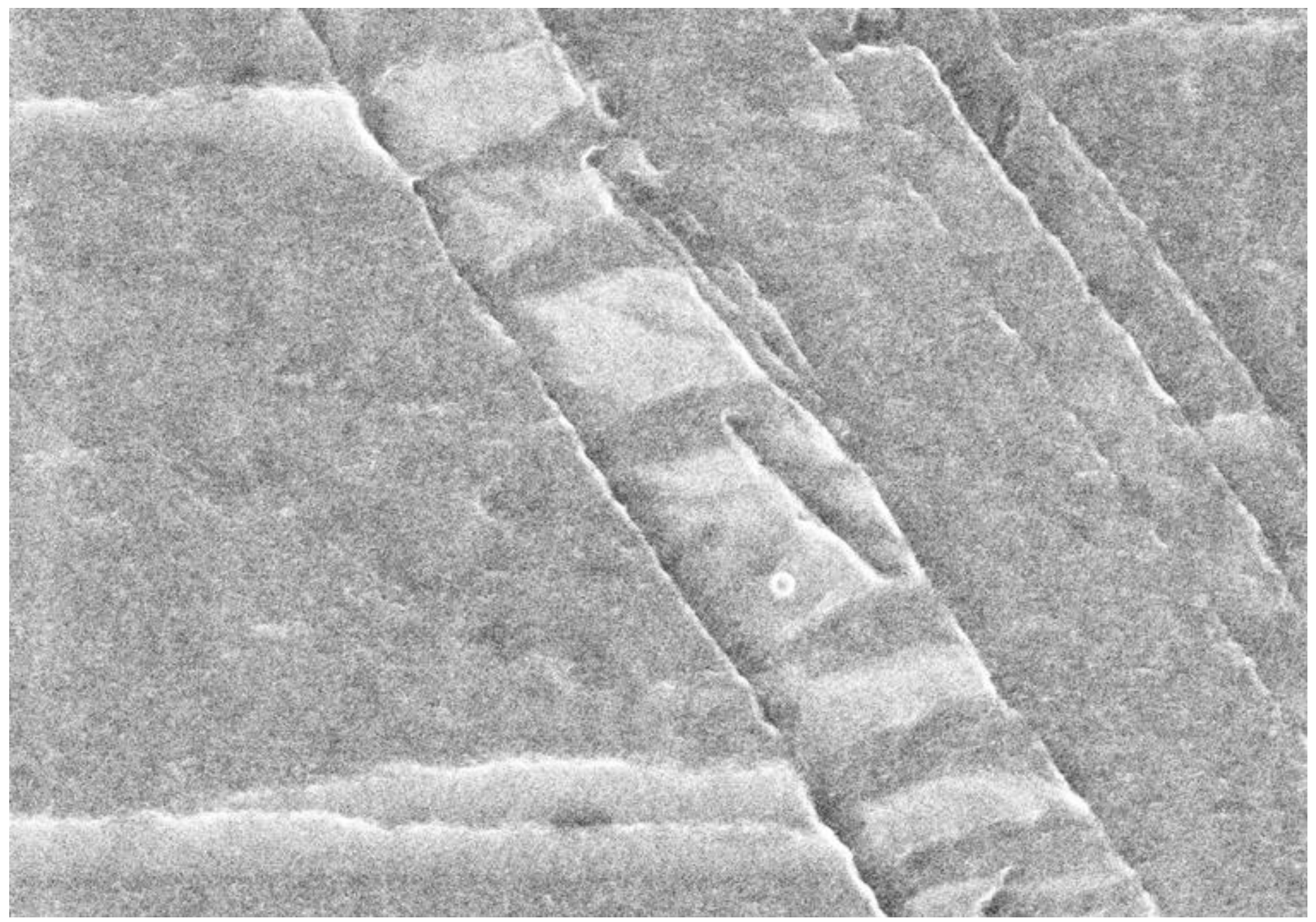

\section{$5 \mu \mathrm{m}$}

Figure 6 

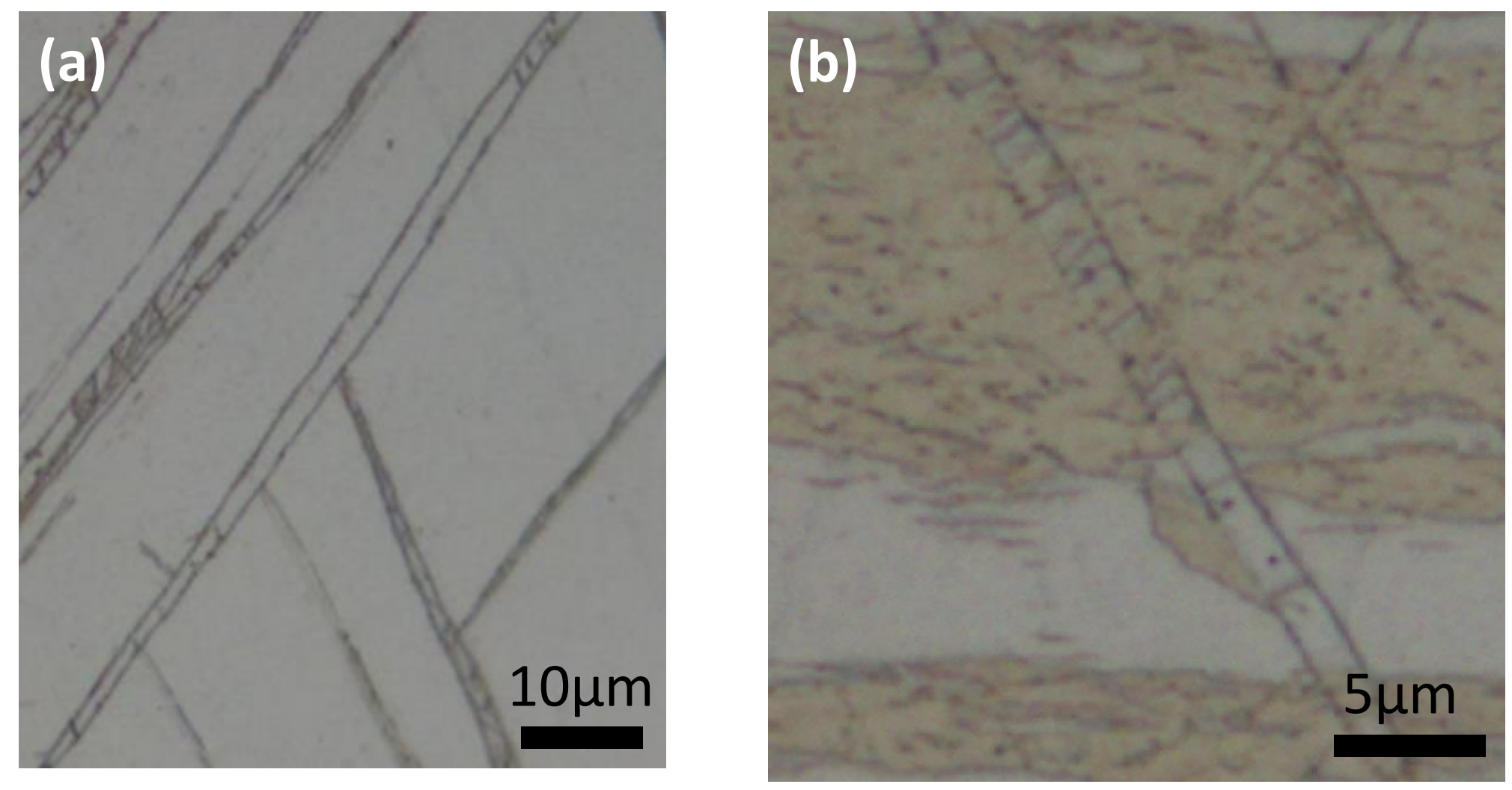

Figure 7 
(i)

original matrix

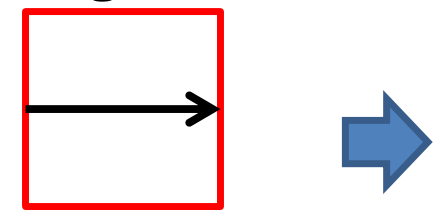

(ii)

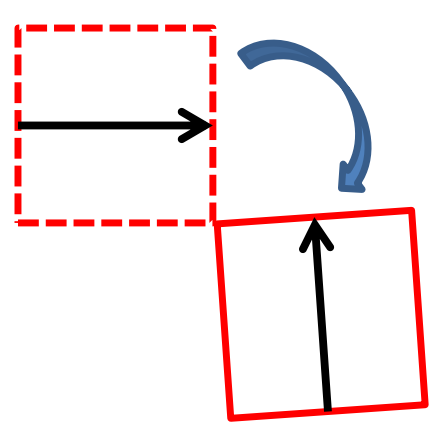

E-T (new matrix)

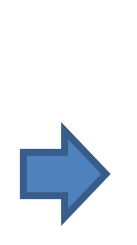

(iii)

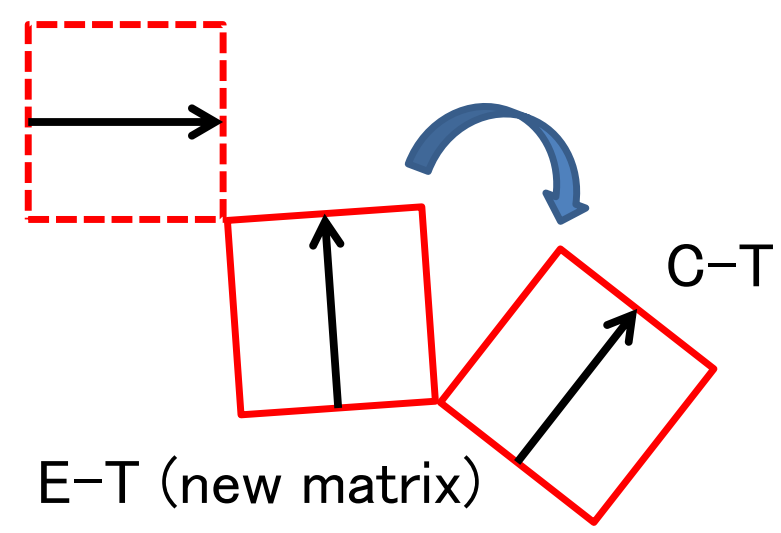

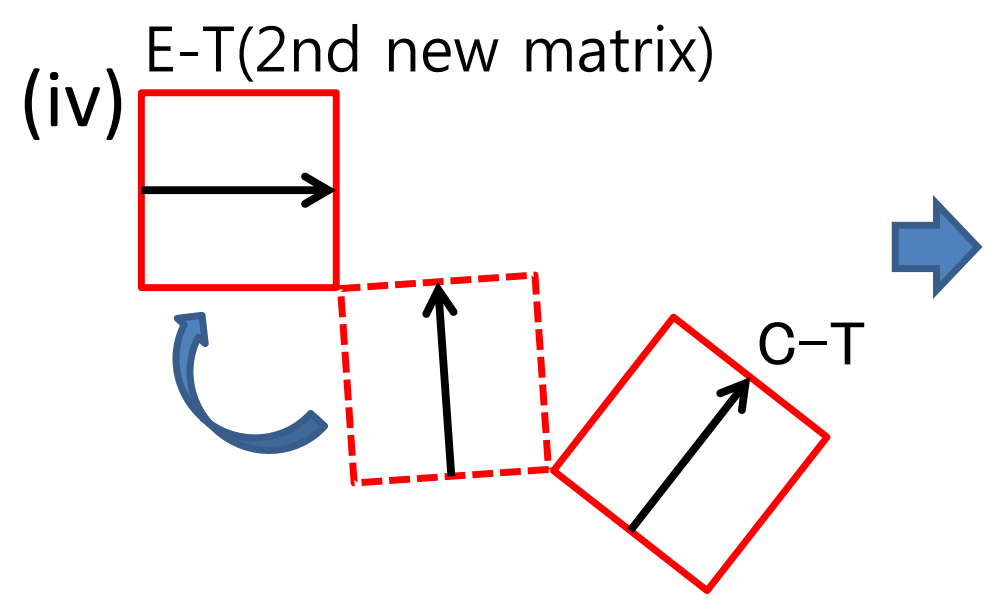

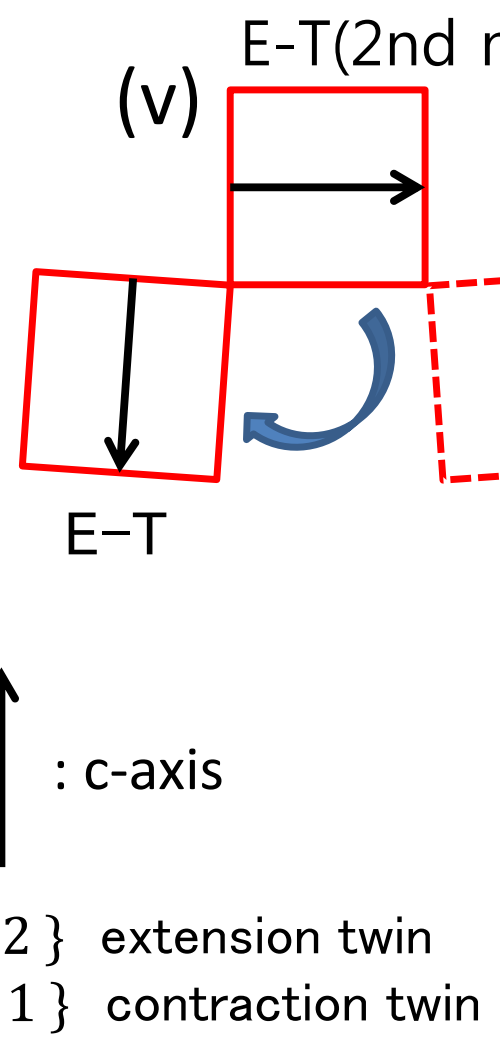

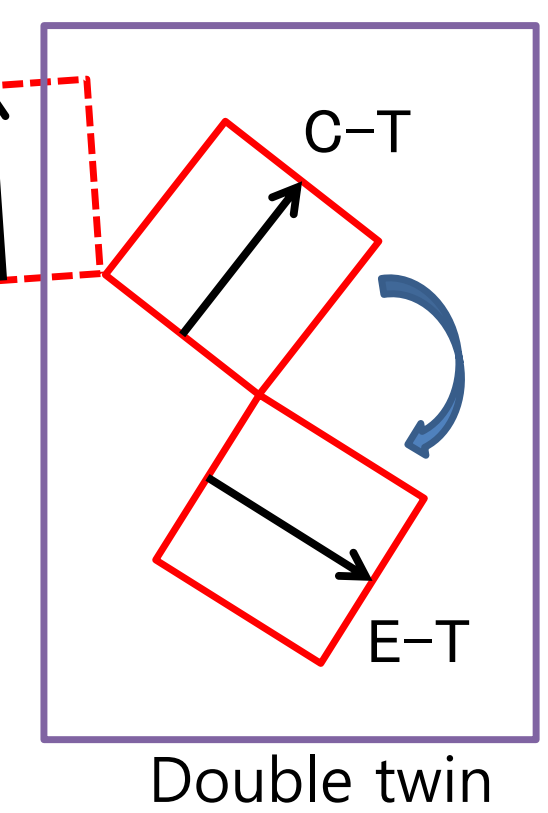

Figure 8 


\section{Matrix}

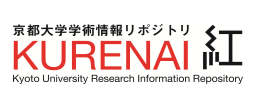

(a)

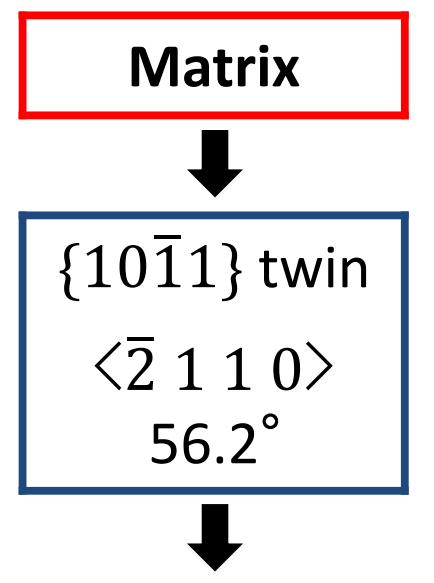

\begin{tabular}{|c|c|}
\hline Type1 & Type2 \\
$\langle\overline{2} 110\rangle$ & $\langle\overline{2} 110\rangle$ \\
$37.6^{\circ}$ & $30.1^{\circ}$ \\
\hline Type3 $^{\circ}$ & Type4 \\
$\langle 34 \overline{7} 2\rangle$ & $\langle 77 \overline{14} 3\rangle$ \\
$66.5^{\circ}$ & $69.8^{\circ}$ \\
\hline
\end{tabular}

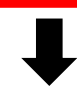

(b)

$\{10 \overline{1} 2\}$ twin

$\langle\overline{2} 110\rangle$

$86.3^{\circ}$

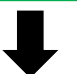

$\{10 \overline{1} 1\}$ twin

$\langle\overline{2} 110\rangle$

37.6

\begin{tabular}{|c|c|}
\hline Type1 & Type2 \\
$\langle\overline{2} 110\rangle$ & $\langle\overline{2} 110\rangle$ \\
$48.7^{\circ}$ & $56.2^{\circ}$ \\
\hline Type3 $^{\circ}$ & Type4 \\
$\langle 6 \overline{28} 22 \overline{9}\rangle$ & $\langle 1 \overline{6} 5 \overline{2}\rangle$ \\
$80.2^{\circ}$ & $73.6^{\circ}$ \\
\hline
\end{tabular}

Figure 9 


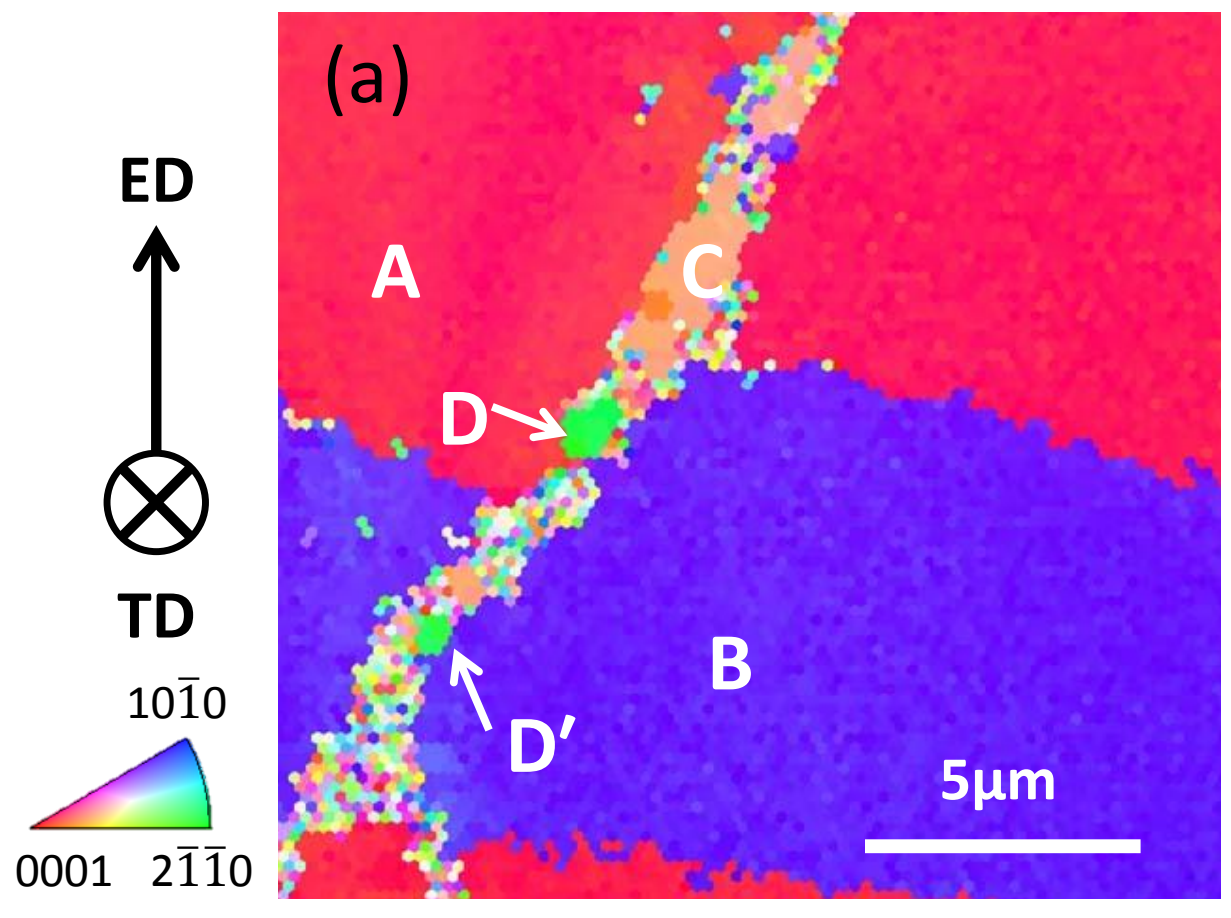

(b)

\begin{tabular}{|l|l|}
\hline \multicolumn{2}{|c|}{ Misorientation relationship } \\
\hline A - B & $<\overline{2} 110>89.6^{\circ}$ \\
\hline A-C & $<\overline{1} 2 \overline{1} 0>40.3^{\circ}$ \\
\hline A - D & $<13 \overline{9} \overline{4} \overline{4}>80.2^{\circ}$ \\
\hline B-C & $<\overline{6} 512>76.8^{\circ}$ \\
\hline B-D & $<1 \overline{1} 0 \overline{2}>31.0^{\circ}$ \\
\hline C-D & $<2 \overline{1} \overline{1} 0>85.5^{\circ}$ \\
\hline
\end{tabular}

(c)

\begin{tabular}{|c|c|}
\hline \multicolumn{2}{|c|}{ Misorientation relationship } \\
\hline$A-B$ & $<\overline{2} 110>89.6^{\circ}$ \\
\hline$A-C$ & $<\overline{1} 2 \overline{1} 0>40.3^{\circ}$ \\
\hline$A-D^{\prime}$ & $<3 \overline{2} \overline{1} \overline{1}>80.1^{\circ}$ \\
\hline$B-C$ & $<\overline{6} 512>76.8^{\circ}$ \\
\hline$B-D^{\prime}$ & $<4 \overline{4} 0 \overline{7}>31.0^{\circ}$ \\
\hline$C-D^{\prime}$ & $<2 \overline{1} \overline{1} 0>87.2^{\circ}$ \\
\hline
\end{tabular}

Figure 10 


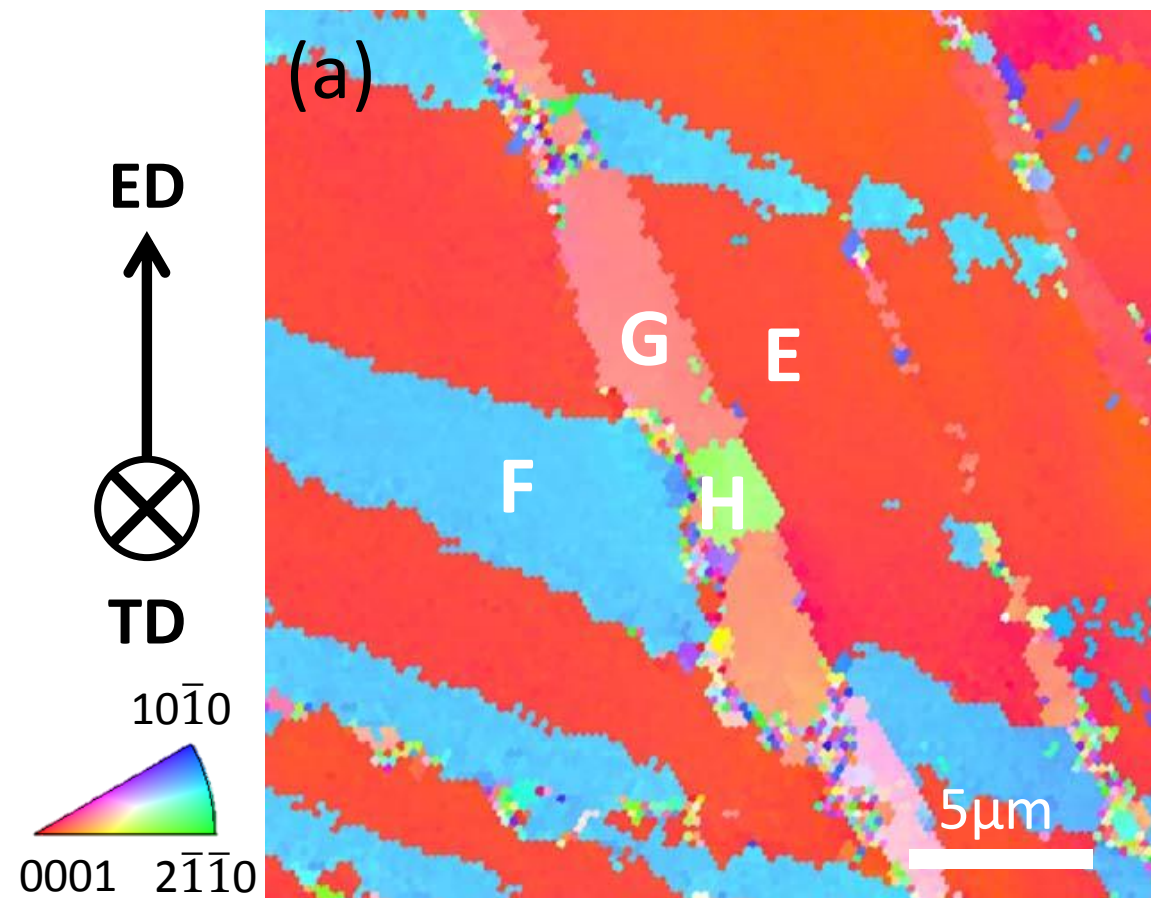

(b)

\begin{tabular}{|c|c|}
\hline \multicolumn{2}{|c|}{ Misorientation relationship } \\
\hline$E-F$ & $<\overline{1} \overline{1} 20>86.4^{\circ}$ \\
\hline$E-G$ & $<2 \overline{1} 0>42.0^{\circ}$ \\
\hline$E-H$ & $<\overline{3} \overline{16} 197>75.0^{\circ}$ \\
\hline$F-G$ & $<\overline{12} \overline{21} 33 \overline{10}>78.1^{\circ}$ \\
\hline$F-H$ & $<116 \overline{17} \overline{24}>30.5^{\circ}$ \\
\hline$G-H$ & $<2221 \overline{43} 0>89.3^{\circ}$ \\
\hline
\end{tabular}

Figure 11 
(a)
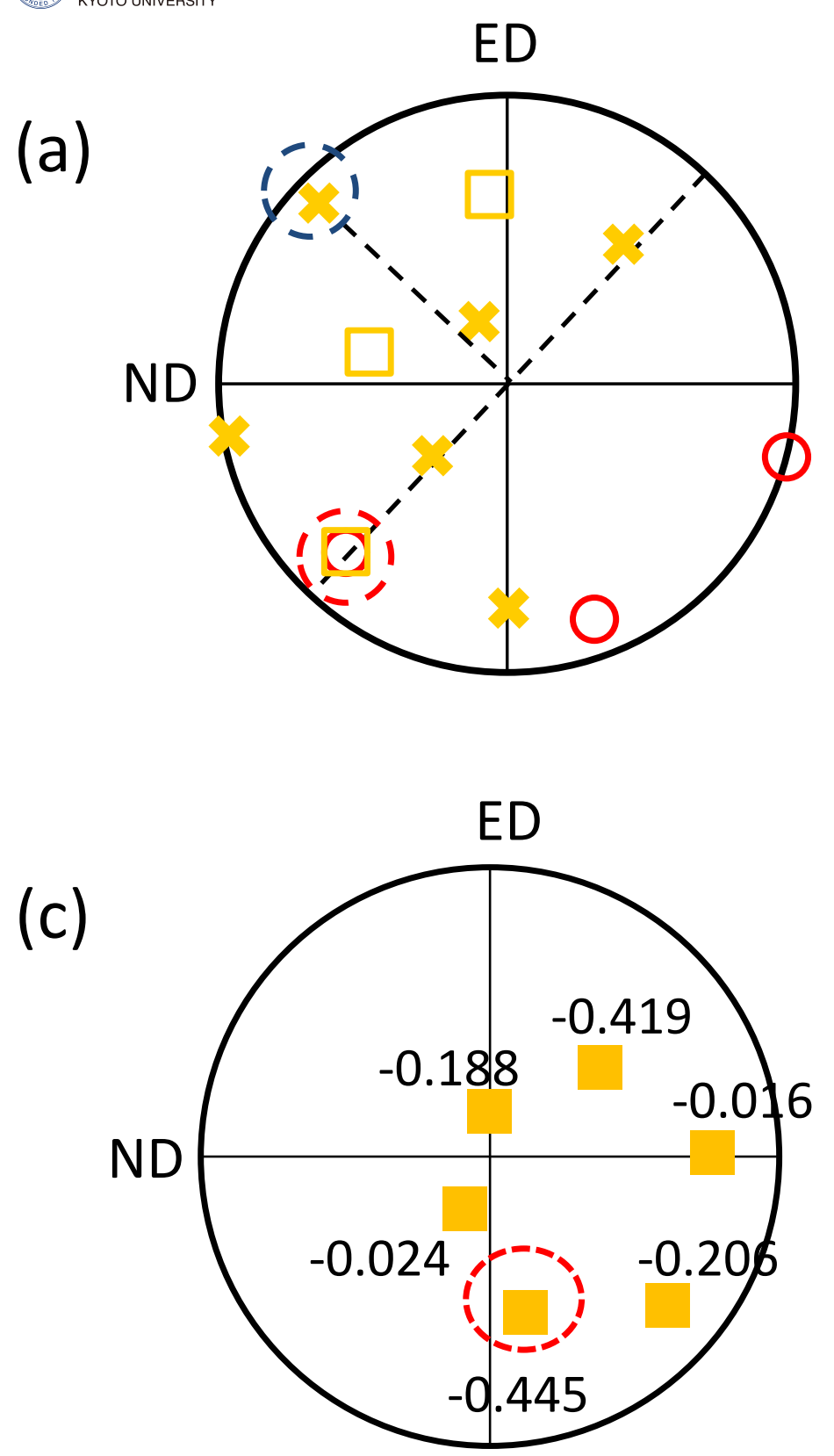

(b)

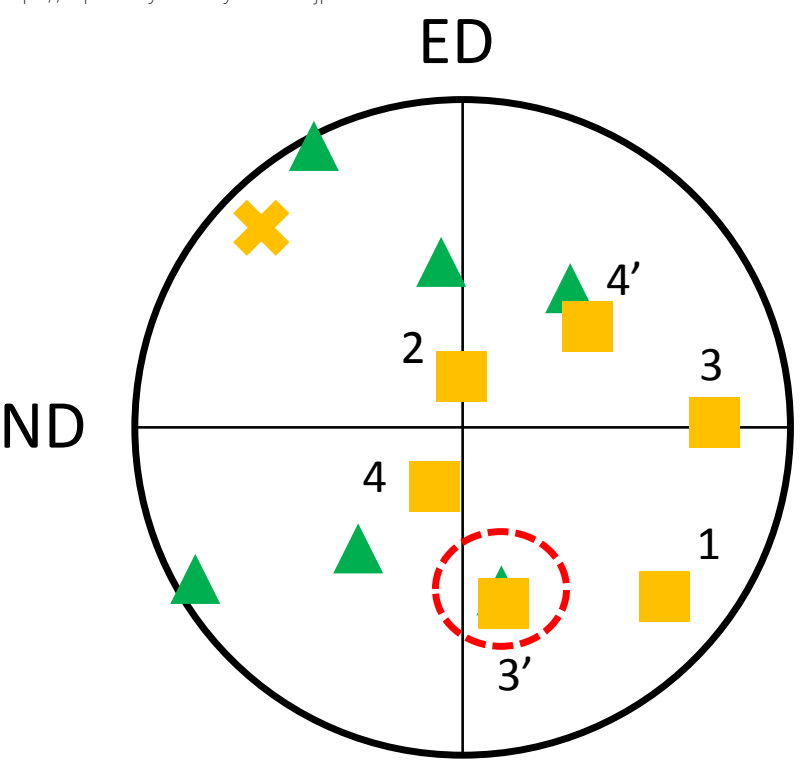

(d)

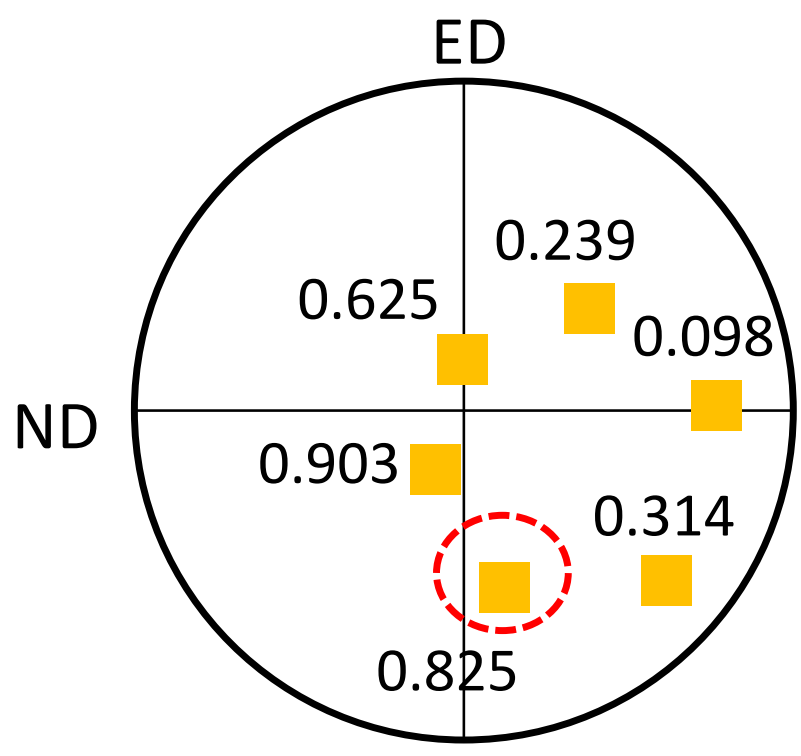

$(\overline{2} 110)$ for $A$

$\square(\overline{2} 110)$ for $C$ (101̄2) for C $\Delta(10 \overline{1} 2)$ for $D$ (101̄1) for C

Figure 12 
(a)
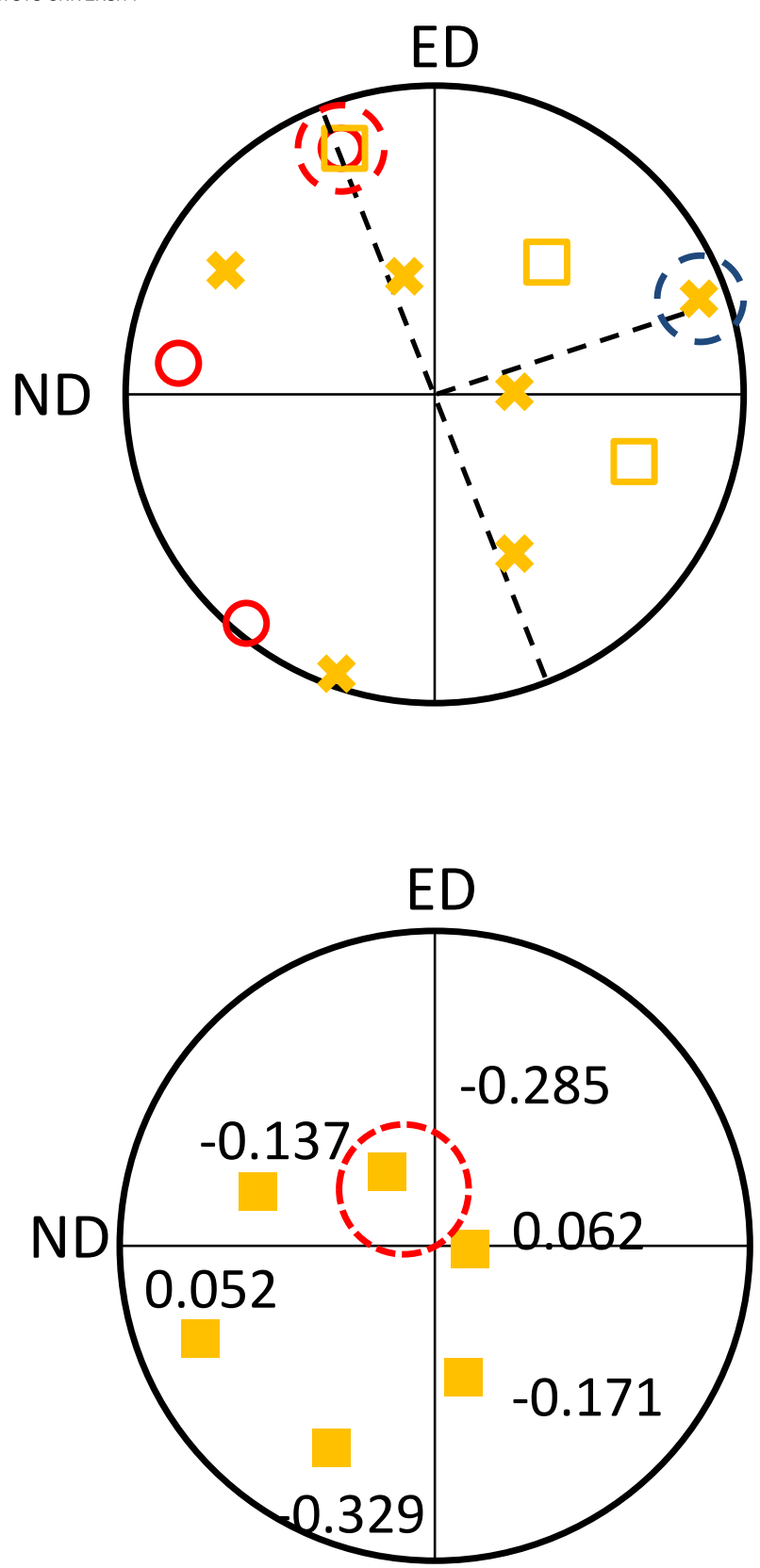

(b)

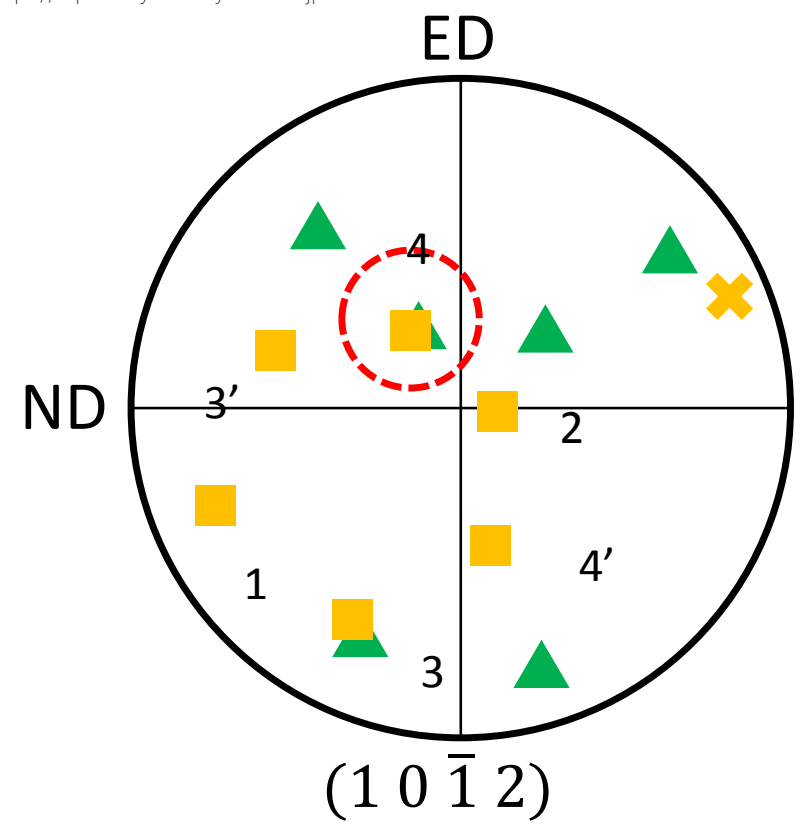

(d)

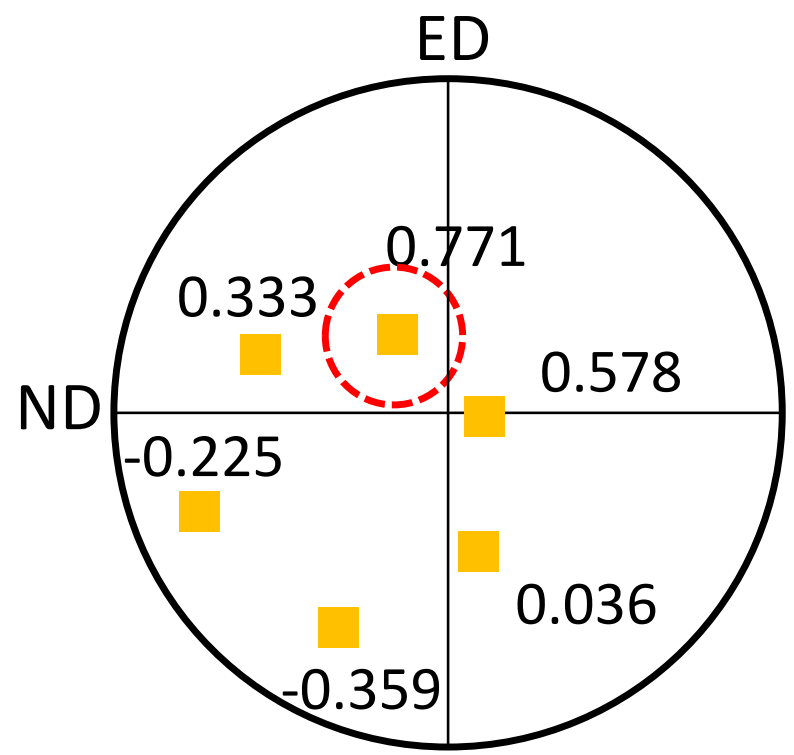

( $\overline{2} 110)$ for $E$

$\square(\overline{2} 110)$ for $G$ (1012) for $G$ $\triangle$ (1012) for $\mathrm{H}$ (1011) for $G$

Figure 13 

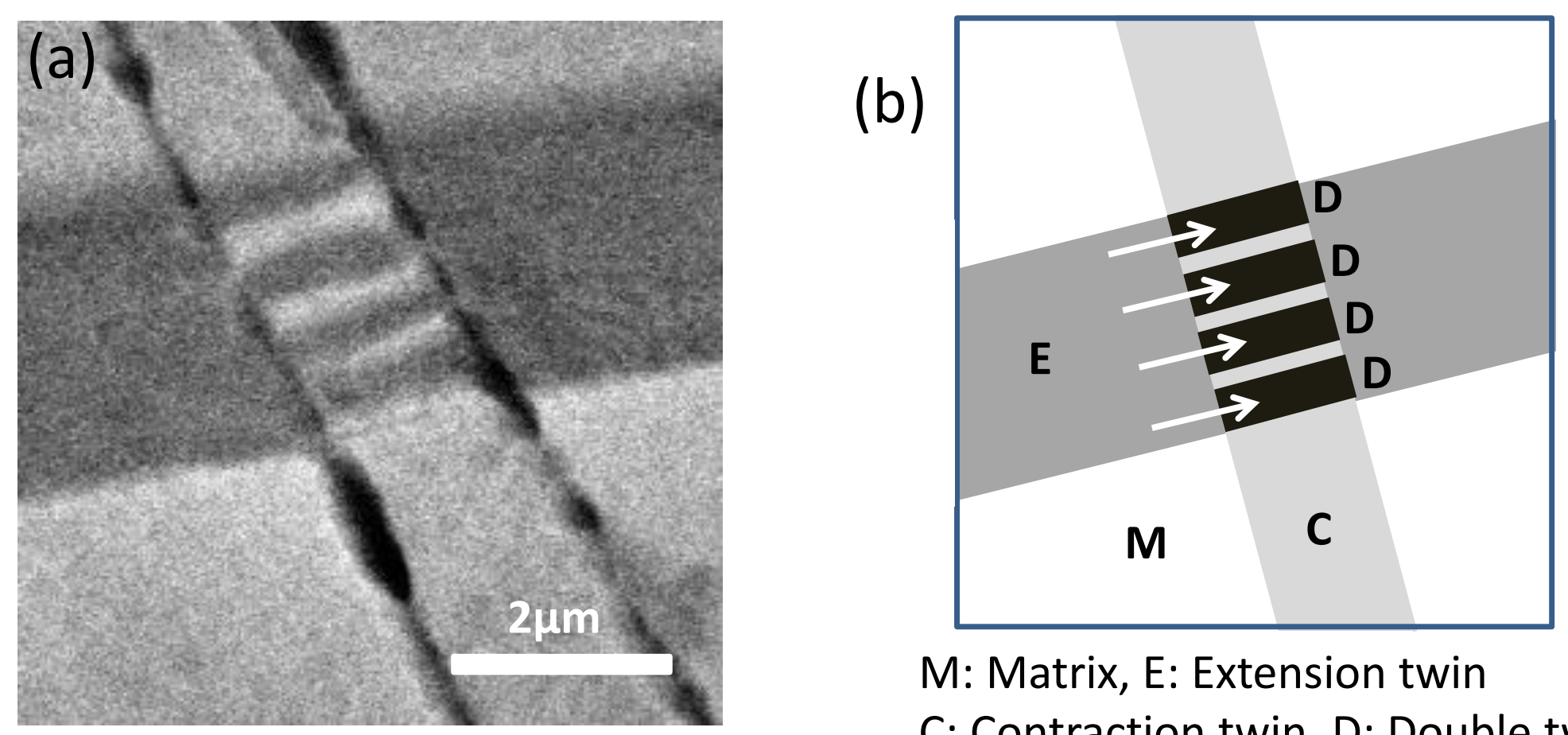

M: Matrix, E: Extension twin

C: Contraction twin, D: Double twin

Figure 14 


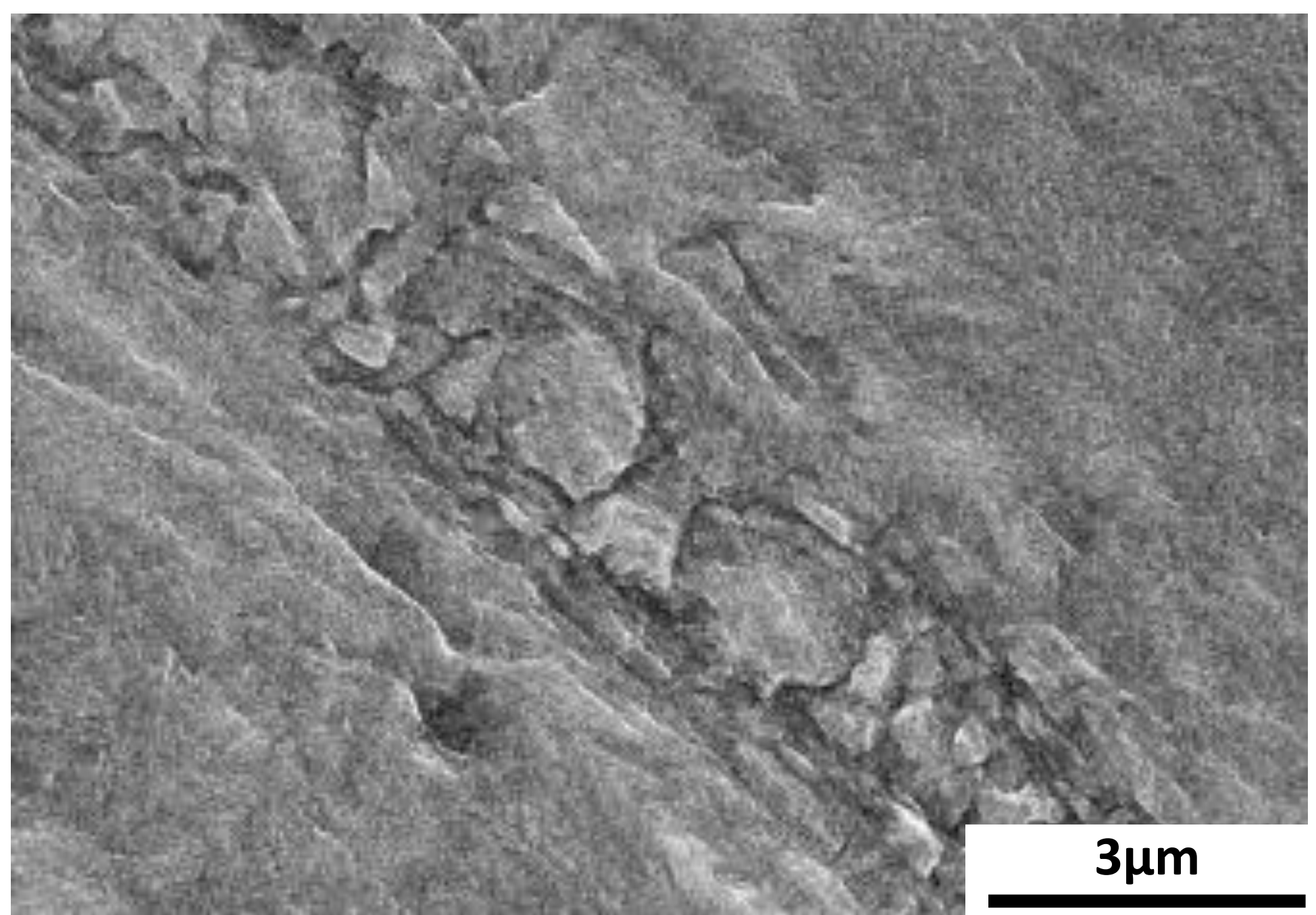

Figure 15 


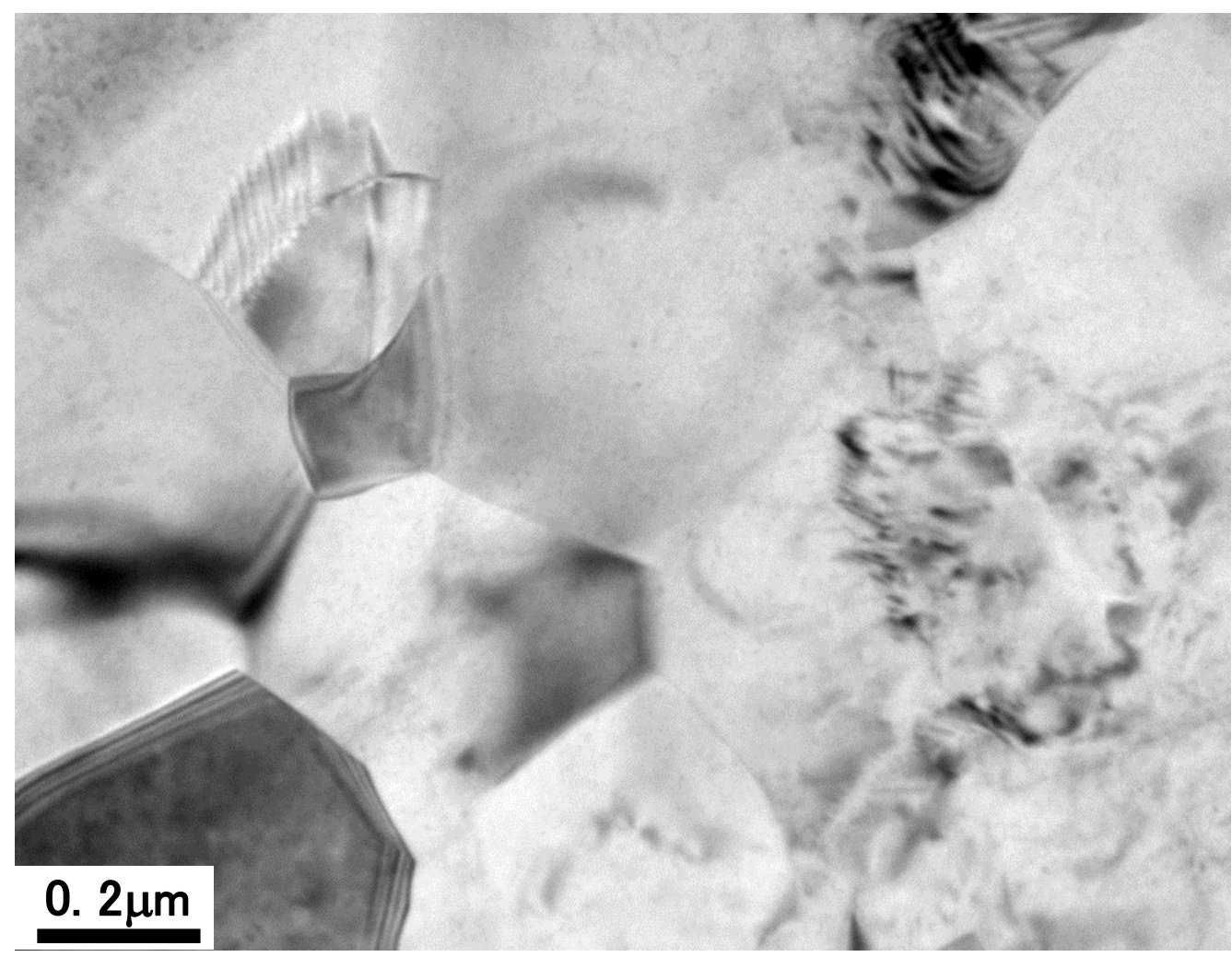

Figure 16 